\title{
EL DEBATE CONSTITUYENTE SOBRE EL TÍTULO I DE LA CONSTITUCIÓN ESPAÑOLA DE 1978, O LA CONSTITUCIÓN "CENADA"
}

\section{THE CONSTITUENT DISCUSIÓN ABOUT TITLE I OF THE SPANISH CONSTITUTION OF 1978 OR THE "DINNERED" CONSTITUTION}

\author{
Esther González-Hernández \\ Universidad Rey Juan Carlos
}

\begin{abstract}
Sumario: I. INTRODUCCIÓN, II. LA "TEORÍA DE LAS GENERACIONES DE DERECHOS", III. EL CAPÍTULO III DEL TÍTULO I DE LA CE/78 O EL "TOTUM REVOLUTUM": A. El "consenso" o las cenas, B. Los derechos en el Anteproyecto de Constitución española, B. Los "Principios rectores de la política social y económica", CONCLUSIONES, BIBLIOGRAFRIA.
\end{abstract}

Resumen: En estas páginas se pretende arrojar algo de luz sobre los debates constituyentes de 1977-1978 sobre el contenido y estructura del Título I de la Constitución española de 1978 y su sistema de derechos fundamentales, una relevante etapa de nuestra reciente historia constitucional. Con este análisis se pretenden aportar nuevos elementos de valoración de los derechos sociales en ella contenidos.

\begin{abstract}
This paper aims to shed some light on the constituent debates of 19771978 on the content and structure of Title I of the Spanish Constitution of 1978 and its system of fundamental rights, an important period of our recent constitutional history. With this analysis, it is intended to provide new elements for a convenient study of the social rights contained therein.
\end{abstract}

Palabras clave: Derechos fundamentales, Título I, Constitución española de 1978, derechos sociales

Key words: Fundamental rights, Title I, Spanish Constitution of 1978, social rights.

"El solo enunciado de este título debe producir, de entrada, una impresión parecida a la que le causara al diputado Koch, en la Asamblea Nacional Constituyente reunido en Weimar, el contenido de la segunda parte de la que sería la "Constitución del Reich" de 11 de agosto de 1919, dedicado a los derechos fundamentales y deberes fundamentales de los alemanes": el intento de abarcar todas las cosas divinas y humanas" "Freiheitsrechte und institutionnelle Garantien der Reichsverfassung”, 1931, en Verfassungsrechtliche Ausfsätz, Belím, 1958). 


\section{INTRODUCCIÓN}

Aunque hayan pasado, "apenas", 40 años, es historia constitucional, pues 40 años a la velocidad que van hoy las cosas es mucho más de, tan solo, 40 años. Estos 40 años, de vigencia de la Constitución de 29 de diciembre de 197, conforman, pues, y se constituyen en un capítulo fundamental de nuestro devenir constitucional tanto pasado como fututo, pues hunde sus raíces en 1977 y 1978, pero proyecta sus consecuencias hasta 2019 y más allá. En definitiva, que como tal historia y de relevancia para el desarrollo y mejora de nuestro sistema constitucional ha de ser analizada, estudiada y, hasta, desmenuzada.

Todo empieza el día en que se celebra la primera sesión de la Comisión de Asuntos constitucionales y libertades públicas. En esta sesión "acababa de hablar Santiago Carrillo y deberá sucederle en el turno de la palabra, Manuel Fraga, y el presidente de la Comisión se equivocó: "El señor Carillo -dijo- tiene la palabra (y el Diario de Sesiones hace constar: "Risas"). Perdón, el señor Fraga.

"Comienza el consenso", fueron las primera palabras que pronunció el señor Fraga"1.

Terminadas las sesiones de esta Comisión, el viernes 28 de julio de 1978, Fernando Álvarez de Miranda, anunciaba que se iba a proceder a la votación de la totalidad del Anteproyecto, sobre el que los profesores De Esteban y López Guerra opinaban: "aceptemos, pues que el proyecto es probablemente el mejor de los posibles"2.

Con afirmaciones de este tipo se fue construyendo, con el paso de los años, una leyenda llena de magia, simbolismo y orgullo que sitúa en la transición y en el "consenso", el gran activo de nuestra historia politica del siglo XX. Esto es, el "método y la concordia como virtud que daba sentido a aquel se concretaron, como es sabido, en nuestra Constitución vigente. Y de ello pervive en la memoria colectiva gran recuerdo"3. Asi se ha afirmado incansablemente, a pesar de que supuso, también, "cierto sacrificio" de las posturas de máximos de los dos grandes partidos "ganadores" de las elecciones de 15 de junio de 1977.

Es precisamente en esos "sacrificios" donde siguen situándose los "puntos de fricción" política y, por ende, constitucional en nuestros días. Todo aquello que se dejó conscientemente abierto o en la ambigüedad, sigue ocupando la actualidad político-constitucional de España. Ello, a pesar de que, tradicionalmente se haya afirmado su "eficacia para salvar los puntos más conflictivos del texto, como eran la forma de gobierno, la cuestión religiosa, el modelo económico, la descentralización territorial, el modo de elegir al Presidente del Gobierno (...) Así los escollos que representaron las más de mil enmiendas en el Congreso o las tantas del Senado pudieron resolverse, a fin de no perderse en

1 Cortes General, Trabajos Parlamentarios, Comisión de Asuntos Constitucionales y Libertades Públicas, sesión de 5 de mayo de 1978, Diario de Sesiones del Congreso, núm, 55, Cortes Generales, Madrid, 1980, p. 2041, cit., García Escudero, José María y García Martínez, Asunción, La Constitución día a día. Los grandes temas de la Constitución de 1978 en el debate parlamentario, Congreso de los Diputados, Madrid, 1998, pp. 23 y 24.

2 De Esteban, Jorge y López Guerra, Luis "En defensa de la Constitución”, Cuadernos para el dialogo, 15 de junio, de 1978, p. 18.

3 Alzaga, Óscar, Del consenso constituyente al conflicto permanente, ed. Trotta/Fundación Alonso Martínez Escudero, Madrid, 2001, p. 12. 
la noche de los tiempos, a través de la técnica del consenso"4. Pero, como trataremos de demostrar en estas páginas, esta afirmación dista, un poco, de ser tan validad. Es posible, pues, identificar en la Constitución española algunos "agujeros negros" (si se me permite la expresión), tanto por su contenido como por su sistemática. Este último es el caso de la ordenación de los derechos fundamentales. Lo usual ha sido que el comentario sobre el proceso constituyente de redacción de los derechos fundamentales desde la sola perspectiva del contenido, uno a uno, de los derechos. A saber, los más conflictivos como el derecho a la vida (art. 15) ${ }^{5}$, el derecho a la educación (art. 27), o la libertad religiosa (art. 16), pero no se encuentra (al menos yo no he dado con él) ningún comentario global sobre la discusión de la sistemática del Título I de nuestra vigente Constitución. De esto es precisamente de lo que trataremos en estas páginas.

Una cuestión, sin duda, de importancia capital, pues aunque a priori, parezca meramente formal, a la larga, tiene una trascendencia y significación que traspasa lo formal para influir, incluso, en la naturaleza jurídica de los derechos en sí mismos.

\section{LA "TEORÍA DE LAS GENERACIONES DE DERECHOS"}

Derivada de cierto "clasicismo" en el estudio de los derechos fundamentales, la Constitución española de 29 de diciembre de 1978 acoge una visión clásica de los derechos, al asumir la "Teoría de las generaciones de derechos", inicialmente formulada por Karel Vasak en $1977^{6}$ y confirmada después en 1979 en la "Lección inaugural" del X Sección de Enseñanza del Instituto Internacional de Derechos Humanos.

Así, la Constitución española de 1978 contemplaría, en su estructura interna, tres generaciones de derechos:

$\checkmark$ Derechos de primera generación o derechos y libertades civiles o de carácter político en la Sección $1^{\mathrm{a}}$, Capítulo II del Título I.

$\checkmark$ 2. Derechos de segunda generación o socio-económicos en la Sección $2^{a}$, Capítulo II del Título I.

$\checkmark$ 3. Derechos de tercera generación de solidaridad o colectivos en el Capítulo III del Título I.

Será esta estructura u ubicación lo que determinará la mayor o menor efectividad, protección y garantías de los derechos. Así, en el caso de los contenidos en el Capítulo III, "el artículo 53.3 CE modula su eficacia, limitándolo

\footnotetext{
4 De Esteban, Jorge, Tratado de Derecho Constitucional-I. Servicio de Publicaciones. UCM, Madrid, 2001, p. 115.

5 Interesante comentario Jorge De Esteban, Jorge y Luis López Guerra, "En defensa de la Constitución”, op. cit., pp. 17 y 18.

6 Vasak. Karel, "Human righsts: a Thirty-Year Struggle: the Sustained efforts to give Force of Law to de Universal Declaration of Human Rights", UNESCO Courier 30: 11, United Nations Educational Scientific and Cultural Organization, Paris, November, 1977.
} 
a informar el ordenamiento jurídico, pero sin dotarlos de plena efectividad"7. Estos últimos, a diferencia de las dos categorias anteriores, en puridad, no serian auténticos "derechos públicos subjetivos" sino meras declaraciones de principios respecto de los poderes públicos, dentro de una categoría de perfiles difusos y que, encuentran una dificil positivación en los ordenamientos jurídicos nacionales", " a modo de "semi-derechos" (si se me permite la expresión) que "se remiten a nuevas exigencias sociales que irrumpen en el panorama politico y que se caracterizan por su pluralidad, por su referencia a la fraternidad, solidaridad, medio ambiente, justicia social, justicia entre generaciones. Quizá el mérito de esta categoría consiste en su plasticidad, en su pluralidad, lo que permite traducir aspiraciones que exceden de los limites de lo jurídico"9, etc. Todo ello, a pesar de que, en palabras de Pérez Luño: "los derechos humanos en su acepción estricta surgieron en el clima cultural ilustrado de la Modernidad. Fueron formulados entonces como categorías intemporales y perpetúas de la naturaleza humana; como un conjunto de facultades jurídicas y políticas propias de todos los hombres y en todos los tiempos"10, pero en su evolución y recorrido posterior nos introduciría en valoraciones tanto de tipo histórico como conceptual, al hilo de su construcción como haz de facultades jurídicas más o menos amplias.

Es por ello, que tiene cierto predicamento todavía la tan traída y llevada expresión de las "generaciones de derechos", que obedecía (al menos inicialmente) a la necesidad de completar las iniciales y muy improvisadas declaraciones de libertades. Surgía necesariamente una segunda generación: la de los derechos económicos, sociales y culturales" y, a partir de la segunda mitad del siglo XX pareció más adecuado hablar de otro grupo o categoria, pues ya se estaba en el fenómeno denominado de la "contaminación de las libertades", esto es, la erosión y degradación que aquejarian a los derechos fundamentales ante determinados usos de las nuevas tecnologías ${ }^{11}$.

Por tanto, las diferencias entre cada una de estas categorias obedecería al diferente momento histórico de gestación, lo que en el ámbito jurídico se traduciría en una dispar protección por parte del ordenamiento jurídico. Así, los derechos comprendidos entre las dos primeras categorías gozarian de más protección, es decir, serían derechos más protegidos por el ordenamiento jurídico

\footnotetext{
7 Canosa Usera, Raúl, "Marco constitucional de la protección de los consumidores y usuarios", en Derecho de los consumidores y usuarios: una perspectiva integral, coord. X. Rodríguez- Arana Muñoz, R. Canosa Usera, L. F. López Álvarez y S. Meseguer Velasco, ed. Centro universitario Villanueva/Netbiblo, La Coruña, 2008, p. 78.

8 Martínez de Pisón Cavero, José Maria, "Las generaciones de derechos humanos", Constitución y derechos fundamentales, coords. J. Betegón Carrillo, F. J. Laporta San Miguel, L. Prieto Sanchís, J. R. de Páramo Argüelles, 2004, p. 423.

9 Ibidem.

10 Pérez Luño, Antonio-Enrique, "Las generaciones de derechos humanos", en Historia de los Derechos Fundamentales, T. IV, Vol. I, Libro I, Parte I, Dykinson, Madrid, 2013, p. 364. Es clásica ya la cita de Peces-Barba, Gregorio, Tránsito de la modernidad y derechos fundamentales, ed. Mézquita, Madrid, 1982. También en Historia de los derechos fundamentales, dir. Gregorio PecesBarba y Eusebio Fernández García, T. I, Dykinson, Madrid, 1998, pp. 13 a 263. Al respecto de que nacen en contextos temporalmente determinadas con la modernidad en el seno de la atmósfera iluminista que inspiró las revoluciones burguesas del siglo XVIII.
}

11 Antonio-Enrique, Pérez Luño, "Las generaciones de derechos humanos, op. cit., p. 368. 
al ser considerados "Derechos públicos subjetivos", es decir, un grupo o conjunto de derechos en los que su titular dispondría de mecanismos jurídicos para exigir que se le restituya en su ejercicio si hubieran sido vulnerados, impedidos $u$ obstaculizados en su disfrute etc. Mientas que los que de tercera generación no gozarian de dicha posibilidad, salvo que así lo permitiese la legislación de desarrollo ${ }^{12}$.

El caso es que, asumir la existencia de "derechos de tercera generación" "entraña determinados riesgos de ambigüedad y equivocidad lingüística. La expresión pudiera entenderse como referida a (...) "nuevos derechos", "derechos de solidaridad", "derechos de la era tecnológica, "derechos emergentes"..., me parece que no contribuyen al logro de su propósito. Estas denominaciones incurren en los mismos defectos de confusión y vaguedad que intentan superar. Hablar de unos "nuevos derechos" como solución clarificadora, exige trazar unos límites precisos y unívocos que distingan los "nuevos" de los "viejos", tarea más que problemática"13. Tal visión falsea la dinámica real de la historia constitucional, pues las citadas familias de derechos, en realidad, irrumpieron de forma simultánea en los primeros textos constitucionales. V. gr. la Constitución francesa de 1793 en que, junto a los clásicos derechos de opinión, prensa y sufragio, ya se mencionaban términos como "socorros públicos". O expresiones como "la sociedad debe la subsistencia a ciudadanos desgraciados, bien procurándoles trabajo, o bien asegurando los medios de existir a los que estén imposibilitados de trabajar" (art. 21) ${ }^{14}$. Por no hablar de la Constitución española de 1812, cuyo artículo 13 sancionaba que el fin de toda sociedad política es el "bienestar de todos los individuos que la componen".

Napoleón y el constitucionalismo de la Restauración los eliminaron temporalmente, pero en 1848 volvieron a rebrotar las reivindicaciones de base social en las Constituciones surgidas de la revoluciones del 4815. Así, la Constitución francesa de 1848 que imponía a los poderes públicos el deber de "poner al alcance de cada uno las instrucciones indispensable para todos los hombres" y de asegurar "la existencia de los ciudadanos necesitados, sea procurando trabajo en los límites de las posibilidades, sea otorgando en defecto de la familia, asistencia a los que no estén en situación de trabajar". Luego vino la Constitución mexicana de 1917 y la de Weimar de 191916 y, en España la de 1931, que incluía la novedosa presencia de estos derechos sociales, emulando a

\footnotetext{
12 Jorge De Esteban, Tratado de Derecho Constitucional-I, op. cit., p. 309.

13 Antonio-Enrique, Pérez Luño, "Las generaciones de derechos humanos, op. cit., pp. 368 y 369.

14 Martín, Sebastián, “Derechos sociales y procesos constituyentes (1931, 1978 ¿2016?)”, Gaceta Sindical, núm. 23 (diciembre), 2014, pp. 42 y 43.

15 Sobre este momento histórico se puede consultar González Hernández, Esther, Breve historia del constitucionalismo común (1787-1931). Exilio politico y "turismo constitucional”, Editorial Ramón Areces/Universidad Rey Juan Carlos, Madrid, 2006.

16 Sobre esta cuestión merece al consulta de Cruz Villalón, Pedro, "Formación y evolución de los derechos fundamentales", en Introducción a los derechos fundamentales, ed. Servicios Jurídicos del Estado, Madrid, 1998, pp. 157 y ss.
} 
la II República francesa e inspiradora en las Constituciones de México, Rusia, Alemania, al consagrar los deberes de protección de los campesinos y pescadores (art. 47), la libertad sindical (art. 39) o la enseñanza primaria gratuita y obligatoria en su art. 48.

Basten estos pequeños ejemplos para argumentar o, cuanto menos, introducir, la idea fundamental que se pretende desarrollar en estas páginas y que no es otra que la de reformular, por lo menos, intentar superar la "teoria de la generación de derechos", pues no se ajusta, ni explica adecuadamente el modelo de derechos fundamentales asumido por nuestra Norma fundamental, que, a priori, acogeria la sistemática de las clásicas tres generaciones:

1. Derechos de primera generación o derechos y libertades civiles o de carácter político: aquellos que se gestaron en los inicios del constitucionalismo liberal de los siglos XVIII y XIX, es decir, los primeros derechos, que encontraron su máximo referente legislativo en la Declaración de los derechos del hombre y del ciudadano de 1789.

2. Derechos de segunda generación o socio-económicos: los derechos surgidos en el periodo de entreguerras de marcado carácter social, es decir, de contenido prestacional.

3. Derechos de tercera generación de solidaridad o colectivos: derechos de los que se empieza a hablar a partir de la segunda Guerra Mundial y que serian beneficiosos para toda la humanidad como el derecho al medio ambiente, derecho a un entorno sano, derecho al patrimonio cultural etc. O para determinados colectivos: tercera edad, menores, discapacitados, consumidores... Esta estaría contenida en el Capítulo III del Título I. Pero vayamos al listado de derechos contenido en el Título I de la Constitución española de 1978, según esta ordenación:

\begin{tabular}{|c|c|c|}
\hline Sección $1^{\text {a }}$, Cap. II & Sección $2^{\mathrm{a}}$, Cap. II & Cap. III \\
\hline $\begin{array}{l}\text { Art. 15: derecho a la vida y a } \\
\text { la integridad fisica, }\end{array}$ & $\begin{array}{l}\text { Art. 30: derecho y el deber } \\
\text { de defender a España. }\end{array}$ & $\begin{array}{l}\text { Art. 39: protección social, } \\
\text { económica y jurídica de la } \\
\text { familia y derechos de los } \\
\text { menores a la igualdad y a } \\
\text { la investigación de la } \\
\text { paternidad. }\end{array}$ \\
\hline $\begin{array}{l}\text { Art. 16: libertad ideológica, } \\
\text { religiosa y religiosa. }\end{array}$ & $\begin{array}{l}\text { Art. 31: deber de } \\
\text { sostenimiento de los gastos } \\
\text { públicos. }\end{array}$ & $\begin{array}{l}\text { Art. 40: promoción de las } \\
\text { condiciones favorables para } \\
\text { el progreso social y } \\
\text { económico y para una } \\
\text { distribución de la renta. }\end{array}$ \\
\hline $\begin{array}{l}\text { Art. 17: derecho a la libertad } \\
\text { y a la seguridad. }\end{array}$ & $\begin{array}{l}\text { Art. 32: derecho a contraer } \\
\text { matrimonio en condiciones } \\
\text { de igualdad entre los } \\
\text { cónyuges. }\end{array}$ & $\begin{array}{l}\text { Art. 41: mantenimiento de } \\
\text { un régimen público de } \\
\text { Seguridad Social, que y } \\
\text { prestaciones } \\
\text { suficientes. }\end{array}$ \\
\hline $\begin{array}{l}\text { Art. 18: derecho al honor, a } \\
\text { la intimidad personal y } \\
\text { familiar y a la propia } \\
\text { imagen, inviolabilidad del } \\
\text { domicilio, Derecho al secreto } \\
\text { de las comunicaciones } \\
\text { postales, telegráficas y } \\
\text { telefónicas y limitación del } \\
\text { uso de la informática. }\end{array}$ & $\begin{array}{l}\text { Art. 33: } \text { derecho a la } \\
\text { propiedad privada y a la } \\
\text { herencia. }\end{array}$ & $\begin{array}{l}\text { Art. 42: salvaguardia de los } \\
\text { derechos económicos y } \\
\text { sociales de los trabajadores } \\
\text { españoles en el extranjero. }\end{array}$ \\
\hline
\end{tabular}




\begin{tabular}{|c|c|c|}
\hline $\begin{array}{l}\text { Art. 19: derecho a elegir } \\
\text { libremente su residencia y a } \\
\text { circular por el territorio } \\
\text { nacional. }\end{array}$ & 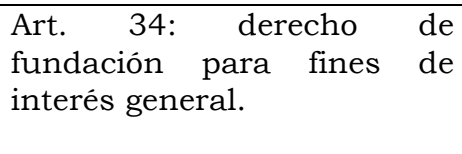 & $\begin{array}{l}\text { Art. 43: derecho a la } \\
\text { protección de la salud. }\end{array}$ \\
\hline $\begin{array}{l}\text { Art. 20: libertad de } \\
\text { expresión y derecho a la } \\
\text { información a la producción } \\
\text { y creación literaria, artística, } \\
\text { científica y técnica, a la } \\
\text { libertad de cátedra. }\end{array}$ & Art. 35: derecho al trabajo. & $\begin{array}{l}\text { Art. 44: promoción del } \\
\text { acceso a la cultura. }\end{array}$ \\
\hline Art. 21: derecho de reunión. & $\begin{array}{l}\text { Art. 36: regulación legal del } \\
\text { régimen jurídico de los } \\
\text { Colegios Profesionales. }\end{array}$ & $\begin{array}{l}\text { Art. 45: derecho a disfrutar } \\
\text { de un medio ambiente } \\
\text { adecuado. }\end{array}$ \\
\hline $\begin{array}{lrll}\text { Art. 22: } & \text { derecho } & \text { de } \\
\text { asociación. } & & \end{array}$ & $\begin{array}{lr}\text { Art. 37: derecho a la } \\
\text { negociación } \\
\text { laboral. }\end{array}$ & $\begin{array}{l}\text { Art. 46: garantía de la } \\
\text { conservación y promoción } \\
\text { del patrimonio histórico, } \\
\text { cultural y artístico. }\end{array}$ \\
\hline $\begin{array}{l}\text { Art. 23: derecho a participar } \\
\text { en los asuntos públicos. }\end{array}$ & Art. 38: libertad de empresa. & $\begin{array}{l}\text { Art. } 47 \text { : derecho a disfrutar } \\
\text { de una vivienda digna y } \\
\text { adecuada. }\end{array}$ \\
\hline $\begin{array}{l}\text { Art. 24: derecho a obtener la } \\
\text { tutela efectiva de los jueces } \\
\text { y tribunales y demás } \\
\text { derechos procesales. }\end{array}$ & & $\begin{array}{l}\text { Art. 48: promoción de las } \\
\text { condiciones para la } \\
\text { participación libre y eficaz } \\
\text { de la juventud. }\end{array}$ \\
\hline $\begin{array}{l}\text { Art.25: principio de legalidad } \\
\text { penal. }\end{array}$ & & $\begin{array}{l}\text { Art. 49: política de } \\
\text { previsión, tratamiento, } \\
\text { rehabilitación e integración } \\
\text { de los disminuidos fisicos, } \\
\text { sensoriales y psiquicos. }\end{array}$ \\
\hline $\begin{array}{l}\text { Art. 26: prohibición de los } \\
\text { Tribunales de Honor. }\end{array}$ & & $\begin{array}{lr}\text { Art. 50: garantía de } & \text { de } \\
\text { pensiones adecuadas } & y \\
\text { periódicamente } & \\
\text { actualizadas } & \end{array}$ \\
\hline $\begin{array}{llll}\text { Art. 27: } & \text { derecho } & \text { a } & \text { la } \\
\text { educación. } & & & \\
\end{array}$ & & $\begin{array}{l}\text { Art. 51: defensa de los } \\
\text { consumidores y usuarios. }\end{array}$ \\
\hline $\begin{array}{l}\text { Art. 28: derecho a sindicarse } \\
\text { libremente y derecho a la } \\
\text { huelga }\end{array}$ & & $\begin{array}{l}\text { Art. 52: regulación legal de } \\
\text { las organizaciones } \\
\text { profesionales que } \\
\text { contribuyan a la defensa de } \\
\text { los intereses. }\end{array}$ \\
\hline $\begin{array}{l}\text { Art. 29: derecho de petición } \\
\text { individual y colectiva. }\end{array}$ & & \\
\hline
\end{tabular}

Según esta explicación, la mayoría de los derechos contenidos en el Cap. III se corresponden con aspectos que tratan de garantizar una mejor calidad de vida. Pero ¿dónde están en este capítulo los nuevos derechos sobre el ámbito de las tecnologías de la información y la comunicación? ¿Y los de la esfera de la bioética o la biotecniología? Ni rastro de ellos. La única referencia está curiosamente en el artículo 18.4, en la Sección $1^{\mathrm{a}}$ del Cap. II, del Tít. I.

Por ello, si ya es dificil sostener la categoria de los "derechos de $3^{a}$ generación", "me parece particularmente desafortunado el uso de términos tales como: "derechos de cuarta generación". Más aún las sucesivas. Tales expresiones incurren en el vicio lógico del quod erat demostrandum, o sea, en dar por demostrado lo que precisamente debe probarse, es decir, estas denominaciones evocan una cierta ingenuidad o ligereza intelectual, al dar por resuelta la problemática de los derechos de tercera generación y abogar por otras 
generaciones sucesivas, cuyo estatus teórico constituye una nebulosa, en palabra de Pérez Luño ${ }^{17}$.

Además, el carácter social de algunos de estos derechos, mal llamados, de tercera generación, es dificilmente discutible. Así lo afirmaba ya en 1979 Jaime Nicolás Muñiz que discrepa de que la Constitución situé "a la mayoría de los derechos sociales bajo la rúbrica de los "principios rectores de la política social y económica", lo que a su juicio no bastaba para negar a los derechos sociales el carácter de derechos fundamentales ${ }^{18}$. Una opinión crítica también la de Hernández Gil que "apreciaba algunas incorreciones o faltas de rigor. Así, comprende entre las libertades públicas aquellas que van dirigidas a una finalidad contraria (...) no se matizaban las diferencias entre derechos y libertades..."19, etc.

Estos derechos, al igual que los clásicos derechos sociales (o de segunda generación), en la mayoría de los casos, pretenden garantizar unos "mínimos de bienestar". Por tanto, una de las claves estará en la expresión "mínimos de bienestar", pues, pretenden superar situaciones de precariedad, intentando generalizar determinados mínimos en asistencia sanitaria, educación, medio ambiente, acceso a la vivienda o soluciones habitacionales etc. El objetivo no es otro que asegurar a los ciudadanos ciertas necesidades individuales básicas que, en las actuales sociedades, adquieren esa dimensión social y de conjunto, innegable. Estas matizaciones o nuevas aportaciones conceptuales sobre los derechos sociales, aparecieron en el panorama doctrinal después de la segunda Guerra Mundial, porque esta supuso un desgraciado paréntesis en el desarrollo de los derechos sociales surgidos en el periodo de entreguerras. En definitiva, como los derechos sociales o de segunda generación estamos antes unos derechos influenciados, en parte, por el contexto económico dado su carácter prestacional. Pero sea como fuere, "sin ellos el ciudadano no puede alcanzar, o ve, seriamente dificultado su desarrollo personal y social (salario mínimo, pensiones por vejez o jubilación, protección económica de menores, ancianos, discapacitados; etc.). Los derechos de prestación conllevan la obligación del Estado de crear y mantener las condiciones materiales para el desenvolvimiento de determinados derechos sin los cuales estos no podrian ser ejercidos por los ciudadanos o lo serían con suma dificultad (derecho a la educación o a la tutela judicial efectiva, etc."20. Es más, incluso aquellos que originariamente no nacieron como prestacionales, en el fondo, lo son. Hasta el punto de poder hablar de "mutación en la naturaleza de alguno derechos de las generaciones anteriores (piénsese en ejemplo tan claro como el derecho a la educación, hoy indiscutiblemente considerado como derechos social)"21. En definitiva, que

17 Antonio-Enrique, Pérez Luño, "Las generaciones de derechos humanos, op. cit., p. 370.

18 Nicolás Muñiz, Jaime, "La declaración de Estado social en la Constitución de 1978", en Libro-homenaje a Manuel García Pelayo, Tomo I, Universidad Central de Venezuela, Caracas, 1980, p. 173.

19 Hernández Gil, Antonio, El cambio politico español y la Constitución, Planeta, Barcelona, 1982 , p. 292.

20 Gómez Sánchez, Yolanda, Derecho Constitucional europeo. Derechos y libertades, Sanz y Torres, Madrid, 2005, p. 63.

21 Sánchez Ferriz, Remedio, Estudios sobre las libertades, Tirant lo Blanch, $2^{\mathrm{a}}$ ed. Valencia, 1995, p. 109. 
"actualmente casi todos los derechos, en mayor o menor medida, son derechos de prestación y requieren algún tipo de actuación positiva del Estado para ser accesible al ciudadano, aunque obviamente, no todos tiene carácter económico"22.

Por tanto, si nos viésemos obligados a hablar de "generaciones" de derechos (cuánto menos dudoso), si quisiésemos seguir esta tradición o costumbre constitucional, no deberíamos considerar, a mi parecer, la existencia de más de dos generaciones:

1. Derechos individuales o de primera generación

2. Derechos sociales o de segunda generación, en los que deberían englobarse también los "derechos de solidaridad", a modo de subespecie que se ha desarrollado en un momento histórico posterior al periodo de entreguerras, simplemente por el estallido de la Segunda Guerra Mundial. Se trata, pues, de unos derechos que se han ido desarrollando o cobrando fuerza a medida que ha ido avanzando el desarrollo del Estado de bienestar.

En realidad, la diferencia entre ambos tipos nunca estuvo en el momento de su gestación sino la naturaleza jurídica del derecho que se contempla. Es más, con el transcurso de los años, los derechos sociales inicialmente admitidos en los Textos constitucionales se consolidan, a la par que surgen nuevas realidades dignas de protección que se van sumando a los derechos sociales originarios. Máxime si se tiene en cuenta el parón que supuso la contienda bélica que, por un lado, frenó su desarrollo pero por otro aceleró la aparición de nuevas realidades necesitadas de protección. Es más, defendemos la consideración de los derechos sociales como un grupo (o lista) permanentemente abierta y susceptible de ampliación. De ahí, que también sea lógico que estos nuevos derechos se reconozcan primero en el ámbito jurisprudencial. Como hablamos de "nuevas realidades" es en la cotidianeidad de las decisiones judiciales donde primeramente se manifiestan, vía conflicto judicial.

\section{EL CAPÍTULO III DEL TÍTULO I DE LA CE/78 O EL “TOTUM REVOLUTUM"}

La Constitución española de 1978 se sumaría, en definitiva, a la práctica constitucional común que distinguiria entre "generaciones de derechos" con efectos doctrinales o pedagógicos al clasificarlos en tres grandes grupos o generaciones. Así, "los derechos de la "primera generación" (o de los textos que los enuncian) están orientados sobre todo a la tutela de las libertades clásicas, que, por un lado, tratan de impedir intromisiones injustificadas en la persona como ser moral y en su esfera privada y, por otro, permitir la formación autónoma de las propias decisiones y la manifestación del pensamiento individual. La "segunda generación" se ocupa sobre todo de la tutela de los "derechos sociales", elaborados sobre las huellas de las doctrinas que llevaron a la realización de Welfare State. Los derechos de la "tercera generación" contestan a necesidades cuya importancia ha sido apreciada más recientemente; se trata de los relativos a la salud, a la vivienda, al entorno o medio etcétera"23. De modo que, los derechos de primera generación estarian regulados en la Sección $1^{\mathrm{a}}$ del 63.

22 Yolanda Gómez Sánchez, Derecho Constitucional europeo. Derechos y libertades, op. cit., p.

23 Pizzorusso, Alessandro, "Las "generaciones" de derechos", Anuario iberoamericano de justicia constitucional, $\mathrm{N}^{\circ} .5,2002$, p. 297. 
Capítulo II del Título I de la $\mathrm{CE} / 78$, los de segunda generación en la Sección $2^{\mathrm{a}}$ del idéntico Capítulo y Título y los de la tercera en el Capítulo III del Título I, lo que, a la postre, supone afirmar que los derechos contenidos en dicho Capítulo III del Título I no son auténticos derechos públicos subjetivos sino meras declaraciones de principios respecto de los poderes públicos.

Esta clásica explicación está plagada, no obstante, de dificultades interpretativas y contradicciones conceptuales. Es más, son varios los preceptos del Capítulo III del Título I de la Constitución de 1978 que no encajan en esta explicación, entre otras cuestiones, porque esta tercera categoría (o generación) de derechos no tiene unos perfiles muy claros y aún son materia de discusión por su incierto reconocimiento, encontrando una dificil positivación en los ordenamientos jurídicos nacionales ${ }^{24}$. Así, como recuerda Martínez de Pisón: "el esquema de las tres generaciones, que se ha generalizado en la teoria de los derechos humanos, no está exento de dificultades en cuando se ahonda un poco en los argumentos históricos y conceptuales y en el análisis de las nuevas realidades" 25 .

Ahora bien, en el caso español, esta situación obedece, no tanto, a una visión limitada de nuestra norma fundamental, sino más bien al particular proceso de redacción del Texto constitucional de 1978. Así, en el Anteproyecto de Constitución tan solo se contemplaban dos categorias de derechos en su inicial Título II: "De los derechos y deberes fundamentales":

1. "De las libertades públicas" en el Capítulo II (arts. 13 a 33)

2. "Principios rectores y derechos económicos y sociales" en el Capítulo III (arts. 34 a 44$)^{26}$.

El cuadro más detallado del inicial “diseño constituyente" del Título II es el siguiente:

\begin{tabular}{|l|l|}
\hline Capítulo II & Capítulo III \\
\hline Art. 13: Dignidad de la persona & $\begin{array}{l}\text { Art. 34: Protección de la familia, } \\
\text { derechos de los menores. }\end{array}$ \\
\hline Art. 14: Igualdad ante la ley & Art. 35: Fomento del pleno empleo \\
\hline Art. 15: Derecho a la vida & $\begin{array}{l}\text { Art. 36: Derecho a la protección de la } \\
\text { salud }\end{array}$ \\
\hline Art. 16: Libertad religiosa & $\begin{array}{l}\text { Art. 37: Fomento y promoción de la } \\
\text { cultura }\end{array}$ \\
\hline $\begin{array}{l}\text { Art. 17: Libertad, detención y habeas } \\
\text { corpus }\end{array}$ & Art. 38:Derecho al medio ambiente \\
\hline
\end{tabular}

24 José María Martínez de Pisón, "Las generaciones de derechos humanos”, op. cit., p. 423.

25 Ibidem, p. 411.

26 Cortes Generales, Constitución española .Trabajos parlamentarios, Boletín Oficial de Cortes, sesión de 5 de enero de 1978, núm. 44, t. I, op. cit., pp. 9 y ss. Afirma en este sentido Antonio Hernández Gil, El cambio politico español y la Constitución, op. cit., p. 292: "La parte del Anteproyecto de Constitución, denominada usualmente dogmática, quizá no con mucha propiedad, recogía la doctrina que, remontándose a las antiguas declaraciones de derechos, se ha convertido modernamente en la regulación internacional y hasta universal de las libertades públicas, los derechos fundamentales y otros cuadros de carácter social y económico (...) nunca me satisfizo esta fórmula, aunque técnicamente fuera posible, a la vez que contribuiría a evitar la excesiva extensión del texto". 


\begin{tabular}{|l|l|}
\hline $\begin{array}{l}\text { Art. 18: Derecho al honor, intimidad } \\
\text { personal y familiar, propia imagen, } \\
\text { inviolabilidad del domicilio, secreto de la } \\
\text { comunicaciones }\end{array}$ & $\begin{array}{l}\text { Art. 39: Salvaguarda y promoción del } \\
\text { patrimonio nacional }\end{array}$ \\
\hline Art. 19: Libertad de residencia y circulación & $\begin{array}{l}\text { Art. 40: Derecho a disfrutar de una } \\
\text { vivienda digna }\end{array}$ \\
\hline $\begin{array}{l}\text { Art. 20: Libertad de expresión y derecho a } \\
\text { la información }\end{array}$ & $\begin{array}{l}\text { Art. 41:Promoción de la participación } \\
\text { de la juventud }\end{array}$ \\
\hline Art. 21: Derecho de reunión & Art. 42: Protección de la discapacidad \\
\hline Art. 22: Derecho de asociación & $\begin{array}{l}\text { Art. 43: Derecho a la pensión y } \\
\text { estabilidad económica de la tercera } \\
\text { edad }\end{array}$ \\
\hline $\begin{array}{l}\text { Art. 23: Derecho a la participación en los } \\
\text { asuntos públicos }\end{array}$ & Art. 44: Derecho de los consumidores \\
\hline $\begin{array}{l}\text { Art. 24: Derecho a la tutela judicial efectiva } \\
\text { y derechos en el seno de un proceso } \\
\text { judicial }\end{array}$ & \\
\hline Art. 25: Derecho-deber de defender España & \\
\hline Art. 26: Deberes tributarios & \\
\hline $\begin{array}{l}\text { Art. 27: Derecho a contraer matrimonio con } \\
\text { igualdad de derechos }\end{array}$ & \\
\hline Art. 28: Derecho a la educación & \\
\hline $\begin{array}{l}\text { Art. 29: Derecho a la propiedad privada y la } \\
\text { herencia }\end{array}$ & \\
\hline Art. 30: Derecho al trabajo & \\
\hline $\begin{array}{l}\text { Art. 31: Derecho a la libre sindicación, } \\
\text { derecho a la negociación colectiva y } \\
\text { derecho a la huelga }\end{array}$ & \\
\hline Art. 32: Libertad de empresa & \\
\hline Art. 33: Derecho de petición & \\
\hline
\end{tabular}

Cierto es que (no descubrimos nada con esto) que el proceso de redacción de la Constitución española de 1978 fue largo (16 meses), fatigoso, arduo e, incluso, en algunos momentos, corrió el riesgo de encallarse. Comenzó (al menos formalmente) el 25 de julio de 1977 con la constitución y nombramiento de los 37 integrantes de la Comisión de Asuntos Constitucionales y libertades públicas ${ }^{27}$, que nombró a la Ponencia de 7 personas, los famosos "Padres de la Constitución" o founding fathers, que tenían como misión ofrecer un primer texto o borrador con el que empezar a trabajar en aquella Constitución que debía redactarse con la colaboración de todos los grupos parlamentarios representados en las nuevas Cortes Generales. Pero nada fue tal y como el guion oficial tenía previsto.

Hagamos, pues, un breve repaso de cómo, de verdad, echó a andar el proceso constituyente, que comienza, incluso, un poco antes de las elecciones de 15 de junio de 1977. Concretamente en el mensaje televisivo con el que Adolfo Suárez cerró el 13 de junio de ese año la primera campaña electoral de la democracia, en que pronunció el famoso "puedo prometer y prometo". Lo que pocos recuerdan es que prometió redactar "una Constitución en colaboración con todos los grupos representados en las Cortes, cualquiera que sea su número de escaños", pero nada fue así. Porque nada estaba más "alejado de las intenciones del Gobierno, cuya primera propuesta partió del entonces ministro de Justicia,

27 Afirmó en su día Solé Tura que "En esta Comisión están representados todos los grupos parlamentarios de manera proporcional” (Solé Tura, Jordi, Los Comunistas y la Constitución, ed. Forma, Madrid, 1978, p. 15). 
Landelino Lavilla, y que consistía en la elaboración de un borrador que se sometería a la consideración del Congreso por parte de su equipo, en el que Miguel Herrero ejercía de secretario general técnico. En concreto Lavilla pretendia que el borrador inicial sobre el que se trabajase fuese el suyo, esto es, el elaborado por Herrero y Rodríguez de Miñón. La idea fue rechazada de plano por la oposición, se propuso la creación de una comisión de expertos, ya que muy pocos diputados sabían algo de constitucionalismo y de Derecho Constitucional. Pero, a pesar de sus carencias académicas, el "Legislador" se resistió a ser mero espectador y palmero de tan histórica y trascendente misión. Por ello, se decidió la creación, dentro de la Comisión de Asuntos Constitucionales y Libertades Públicas del Congreso, de un equipo de ponentes para redactar la nueva Carta Magna. Y ahí empezó la batalla política"28, pues, como recuerda Solé Tura "la elección de la ponencia presentó serios problemas. En un primer momento, los dos grupos parlamentarios con mayor representación -la UCD y los Socialistasintentaron llevar las cosas al terreno del bipartidismos puro y simple, reduciendo las minorías a simples satélites parlamentarios de uno $u$ otro. La primera propuesta que presentaron los dos grupos era formar una ponencia de 5 miembros, 3 de UCD y 2 socialistas (...) Esta propuesta fue rechazada por los grupos minoritarios. Y antes de la elección definitiva de la ponencia se entabló una dura discusión en la que el grupo parlamentario Comunista planteó que ningún grupo parlamentario podia quedar excluido de esta tarea fundamental"29. En realidad, según Charles T. Powell, primeramente se pensó en que la ponencia contase solo con representantes de la UCD de Suárez y del PSOE de Felipe González, pero los socialistas cediesen dos puestos a la minoria vasco-catalana, mientas que el resto de minorías insistían en el número de 9 ponentes. Los socialistas no ponían peros a que se incorporasen otras formaciones, con la sola condición: que no entraran ni Enrique Tierno Galván ni Raúl Morodo ${ }^{30}$. Al final se

28 Palmero, Fernando, "Siete 'padres' de la Constitución que pudieron ser nueve", (URL: https://www.elmundo.es/espana/constitucion-espanola-40-

aniversario/2018/12/05/5c07f1fcfdddffd7678b4716.html, fecha de consulta: 22 de abril de 2019).

29 Solé Tura, Jordi, Los Comunistas y la Constitución, op. cit., p. 16.

30 Powell, Charles T., España en democracia (1975-2000), Plaza y Janés, Barcelona, 2001, p. 221. El Preámbulo, no obstante, fue redactado por Morodo y Tierno Galván. Sobre las vicisitudes del Preámbulo en el proceso constituyente, explica Morodo, Rául, "Proceso constituyente y nueva Constitución española: Anotaciones al Preámbulo constitucional”, Revista de Derecho político, núm. 1, 1978, p. 6 como "la última votación del Congreso fue para el texto del Preámbulo. Por razones, más de táctica de los grupos parlamentarios, que doctrinal sistemática, desde la discusión en Comisión -ya que la Ponencia no aceptó preámbulo alguno a la Constitución-, las enmiendas (grupo mixto y UCD) que incorporaban un Preámbulo fueron pospuestas para la discusión final. Y así, siguiendo con este orden, la votación final del texto negociado, entre los autores de la enmienda y algunos miembros de la Ponencia, en el Pleno se votó y aprobó por 286 votos a favor, 2 en contra y 2 abstenciones" (Diario de Sesiones del Congreso de los Diputados, Comisión de Asuntos Constitucionales y Libertades Públicas, núm., 64, de 11 de mayo de 1978, p. 2161). También Tierno Galván, Enrique, "Sobre el Preámbulo de la Constitución española", manuscrito inédito, 1979, Fondo de Documentación Jurídica del Centro de Estudios Políticos y Constitucionales, pp. 1 y 12 donde deja clara su autoria junto con la de otros compañeros, si bien no dicen quienes y añade que "Cuando se redactó el preámbulo inicial de la Constitución española de 1978 se pensó que no tuviera la consideración de norma textual de ningún "rango" o clase", aunque desde un punto de vista político y sociológico es "la fórmula explícita de un compromiso" (Ibidem, p. 4). Explica, además, como la tarde en que se reunieron los portavoces de los grupos parlamentarios, asesinaban en Madrid a dos jefes superiores del Ejército. De ahí que 
aceptó que fueran 7 y que hubiese un representante del PCE. Por tanto, a diferencia de la Comisión Constitucional, la Ponencia no reflejaba proporcionalmente la configuración ideológica de las Cámaras, entre otros motivos, porque Gregorio Peces-Barba sería el único que defendiese la posición socialista, que, además, contaba ya con un proyecto de Constitución elaborado por Jorge de Esteban, que el propio González le había encargado en enero de 1977, publicado integramente recientemente ${ }^{31}$.

El caso es que, al final, quedó integrada por los siete conocidos como "Padres de la Constitución", que se alinearon de la siguiente manera: 3 en representación de UCD (Gabriel Cisneros, Miguel Herrero y Rodríguez de Miñón y José Pedro Pérez-Llorca), 1 por el PSOE (Gregorio Peces-Barba), Manuel Fraga por AP, Jordi Solé Tura por el PCE y Roca, que, en teoría representaba a los nacionalismos catalán y vasco.

Es en este momento, una vez constituida la Ponencia, cuando la batalla politica se torna en "batalla" constitucional, porque habia que tomar decisiones que marcarían de forma decisiva el devenir de la "nueva España constitucional". El primero de los escollos que tuvieron que superar fue un cuestión de partida y de concepto de relevante importancia, hasta el punto de que el análisis de estas páginas parte, en parte (valga la redundancia) y en casi todo, de ese primer obstáculo: una Constitución completa con su parte orgánica y dogmática, o más escueta centrada solo en la parte orgánica con apenas una alusión a los tratados sobre derechos fundamentales ratificados por España en materia de derechos.

Los de Herrero, esto es, la UCD, quería una "Constitución utilitaria" frente a una "Constitución ideológico-programática" ${ }^{2}$, que prefería Peces-Barba. Es decir, defendian que el consenso debía ser sustituido por el silencio en donde no era posible la concurrencia de criterios $^{33}$. Peces-Barba logró imponer su criterio de

no hubo discusión, pues esa misma tarde el Pleno del Congreso aprobaba el texto. Sí se discutió en el Senado, aunque brevemente, fundamentalmente por Ollero y Sánchez Agesta: "El texto aprobado difiere sustancialmente del proyecto inicial por la supresión del primer párrafo. En lo demás, los cambios no han sido sustanciales [...] Por último observaré que no ha habido comentarios de prensa sobre el preámbulo" (Ibídem, pp. 4 y 5). También, aunque no de un modo central Lucas Verdú, Pablo "Constitución española de 1978 y sociedad democrática avanzada", Revista de Derecho Político, Núm. 10, 1981.

31 De Esteban, Jorge, "Proyecto de unas bases constitucionales para España (Con el acuerdo del PSOE, PNV y el Equipo de la Democracia Cristiana. Hecho en Madrid, en febrero de 1977. Documento histórico no publicado nunca íntegramente hasta ahora", en, en España constitucional (1978-2018): Trayectorias y perspectivas, dir. Benigno Pendás, Esther González y Rafael Rubio (coords.), t. I., Centro de Estudios Políticos y Constitucionales, Madrid, 2018, pp.193 a 218 , en que explica como en diciembre de 1976 recibe una llamada de Felipe González para solicitarle la redacción de un borrador de Constitución, procediendo así a redactar unas bases de la futura Constitución española que le entregó a principios de marzo de 1977 que "después, quien lo utilizó ampliamente fue Gregorio Peces-Barba, que se convertiria, por decirlo así, en el "constitucionalista del PSOE a partir de la Conferencia de Sigüenza convocada en agosto de 1977 y a la que sorprendentemente no fui invitado. Sea como sea, el hecho es que el 60 por ciento de lo que expuse en el documento que redacté, pasaria después, como se puede comprobar, al texto definitivo de la Constitución" (p. 194).

32 Herrero de Miñón, Miguel, "Falsas y verdaderas vías del consenso constitucional", Revista de Estudios Politicos, núm. 9, 1979, p. 80.

33 Freixes San Juan, $\mathrm{M}^{\mathrm{a}}$ T., "Crónica de una Constitución consensuada”, Revista de Estudios Políticos, núm. 40 (julio-agosto), 1984, p. 105. 
elaborar una Constitución larga y detallada, frente a la opinión de Herrero, que la prefería breve ${ }^{34}$, pero fue la UCD la que consiguió imponer sus posiciones más conservadoras y pecatas en materia de derechos gracias a su alianza con Fraga y Roca, lo que provocó la salida de la Ponencia del representante socialista que, como explica Powell, accedió sin embargo a firmar el texto definitivo ${ }^{35}$.

Sea como fuere, esta Ponencia redactó un primer borrador entre los meses de julio a diciembre de $1977^{36}$, cuyo primera versión se publicó el 5 de enero de 1977 en el Boletín Oficial de Cortes, que supuso el plazo de 20 días (si bien posteriormente ampliado) para la presentación de enmiendas ${ }^{37}$ por los grupos parlamentarios y diputados. Tras la aceptación de algunas el texto estuvo ultimado para abril. El Informe de la Ponencia comenzó, pues, su debate, el 5 de mayo en la Comisión de Asuntos Constitucionales y Libertades Públicas, hasta el 20 de junio en que pasó al Pleno que inició sus debates el 4 de julio y hasta el 21 del dicho mes $^{38}$. Este fue el momento clave para la formación definitiva de la opinión de la ponencia ${ }^{39}$, más concretamente los meses de febrero a abril en que "se pretendió un primer modelo, donde los promotores del consenso eran UCD y AP, que tenian mayoría en la Ponencia. Aquí la iniciativa era de centro moderado y de la derecha" 40 .

La UCD, con el apoyo de Fraga y Roca, tenía mayoría, lo que provocó la salida de la Ponencia de Peces-Barba el 6 de marzo, manifiestamente irritado con la imposibilidad de oponerse a esta estrategia ${ }^{41}$. En realidad, afirma Powell que "con el visto bueno el Ministro J. Lavilla, que supervisaba los trabajos de los ponente centristas por delegación de Suárez, a lo largo de los meses Herrero fue forjando un pacto tácito con Fraga y Roca que le permitió imponer, sin excesivas dificultades, los textos defendidos por su partido"42. Peces-Barba, no obstante,

34 Fernando Palmero, "Siete 'padres' de la Constitución que pudieron ser nueve", op. cit.

35 Charles T. Powell, España en democracia (1975-2000)... op. cit., p. 223: “durante la primera fase del proceso constituyente, protagonizado por la Ponencia, se manifestaron con claridad ciertas diferencias de enfoque entre los representantes de los distintos partidos. Herrero de Miñón era partidario de una Constitución breve, centrada en la organización de poderes, sin que estimara necesario un largo catálogo de derechos, que podrian ser sustituidos por una referencia al acatamiento de los textos internacionales vigentes. Peces-Barba, en cambio, defendió la necesidad de un texto más extenso, con una parte dogmática que constitucionalizara los derechos y libertades, así como su garantía efectiva ante los Tribunales. Por su parte, Fraga (...) se inclinó inicialmente por un conjunto de leyes constitucionales al estilo de las de la III República francesa (...) Tano el ponente comunista, Solé Tura, como el de minoría catalana, Rocas, se mostraron más cercanos al planteamiento de Peces-Barba, siendo esto el que al final se impuso"

${ }^{36}$ Las Actas de la Ponencia se publicaron en la Revista de las Cortes Generales núm. 2 de 1984.

37 La Ponencia tuvo que asimilar y analizar 3100 enmiendas contenidas en 779 escritos admitidos a trámite.

38 De aquí pasó al Senado que se reunió desde el 18 de agosto al 14 de septiembre y después a la Comisión Mixta que emitió su Dictamen el 26 de octubre.

39 Peces-Barba, Gregorio, La democracia en España. Experiencias y reflexiones, ed. Temas de Hoy, Madrid, 1996, pp. 183 y 184.

40 Ibidem, p. 184.

41 Charles T. Powell, España en democracia (1975-2000)... op. cit., p. 223.

42 Ibidem, p. 223. 
accedió a firmar el texto final ${ }^{43}$. Si bien esto no supondría un acuerdo definitivo, ni mucho menos. En cualquier caso, fue este el que pasó a la Comisión de Asuntos Constitucionales y Libertades Públicas en donde la mayoría de los artículos se aprobaron, y se aprobaban, sin remisión, por 19 votos (los de UCD y AP) contra 17, pero donde "Herrero de Miñón volvió a insistir en la remisión de la "polémica parte dogmática" a los textos internacionales y, a pesar de que en la reuniones de la Ponencia la UCD no se opuso a las garantías de los principios rectores establecidas por el art. 48.3 del informe, el citado ponente se manifestó en contra de que la protección a estos derechos incluyera su alegación antes la jurisdicción ordinaria mediante los procedimientos establecidos en las leyes que los desarrollen" 44 .

Por este motivo, es decir, porque pareciese que todo estaba ya decidido en un sentido, digamos, "de derechas" o, cuanto menos, más conservador, el PSOE volvió a amenazar con abandonar la Comisión el 18 de mayo. Y es que las Cortes salidas de las elecciones del 77 parecian ligeramente orientadas al centroderecha. Había que lograr un "acuerdo", siquiera "de minimos" (valores superiores, definición del Estado, forma de Gobierno, organización territorial y sistema de derechos fundamentales y libertades públicas) ${ }^{45}$ en los puntos clave de la futura Constitución. Al menos, los pilares que la sustentarian deberían ser firmes y para eso nada mejor que el acuerdo casi unánime.

Fue así como Suárez encomendó a Abril Martorell que hiciese lo posible por reconducir la situación que, sin duda, se había tornado "azul casi negro" y que hacía peligrar un proceso ya de por sí fatigoso.

\section{A. E1 "consenso" o las cenas}

Recuerda José Pedro Pérez-Llorca que la "mecánica fue la elaboración lenta y por sedimentaciones y cristalizaciones sucesivas de un texto que tardó varios meses en convertirse en un primer Anteproyecto. Mediante esta técnica de elaboración, a través del "aparcamiento" sucesivo de cuanto tema conflictivo iba apareciendo -lo que era harto frecuente-, la norma se fue elaborando, mediante el cierre de acuerdos políticos, alli donde primero se podian concluir, articulando luego textos sobre ellos y creando una especie de primera red de preceptos articulados, cuyas mallas, amplísimas al principio, fueron disminuyendo lentamente de tamaño mediante la conclusión de sucesivos acuerdos, que permitirian hacer otros textos, hasta formar un tejido más denso y tupido, para llegar finalmente a la redacción del primer Proyecto elaborado por la Ponencia. Publicado el Anteproyecto y presentadas las enmiendas de los Grupos parlamentarios, no pocas testimoniales, la Ponencia volvió a trabajar de manera reservada hasta publicar el Proyecto. Luego vio el trabajo de la Comisión. En esta etapa empiezan las cenas del consenso, que luego se convierten en reuniones,

43 Gregorio, Peces-Barba, La democracia en España. Experiencias y reflexiones, op, cit., p. 110114 y $123-127$.

44 María Teresa Freixes, “Crónica de una Constitución consensuada”, op. cit., p. 114. Las reflexiones de Herrero de Miñón en el Boletín Oficial de las Cortes, núm. 82, de 17 de abril de 1978, en concreto en el Diario de Sesiones del Congreso, núm. 51 de la Comisión de Asuntos Constitucionales de 5 de mayo de 1978.

45 Gregorio, Peces-Barba, La democracia en España. Experiencias y reflexiones, op. cit., p. 178. 
siempre discretas o reservadas, abiertas a los lideres de los partidos [...] En estas sesiones nocturnas y maratonianas, se cerraron las últimas mallas abiertas, se redactaron textos, no muchos, pero todos importantes, y se profundizó en un principio ya establecido46". He aquí, cuando de verdad empezó a gestarse el tan traído y llevado "consenso" que, a su vez, supuso que Herrero y Lavilla abandonasen sus "tareas constitucionales" 47 . A partir de aquí, es decir, a partir del 22 de mayo la Constitución se gestó de noche y en interminables y frecuentes cenas entre los dos protagonistas del proceso constituyente: Abril Martorell y Alfonso Guerra ${ }^{48}$.

En esta fecha del 22 de mayo "se reunieron los principales parlamentarios de UCD y del PSOE en un conocido restaurante para buscar fórmulas de entendimiento que se concretaron en la redacción pactada de los artículos 26 a 50; y que el día 29 del mismo mes comenzaron a celebrarse reuniones nocturnas de representantes de los grupos parlamentarios, en despachos y bufetes particulares de distintos diputados, para buscar el consenso en relación a otros artículos de la Constitución, pendientes de aprobación"49.

Se inicia así una nueva fase de "acuerdos" tomados fuera del hemiciclo por parte de los diversos representantes de UCD, PSOE, Grupo Parlamentario Comunista y Minoría Catalana"50. Por tanto, que hubo mucho de "acuerdo de mantel" o de "copa y puro" en el proceso de aprobación de nuestra Carta Magna es un secreto a voces. Pero como quizás esto no resultaba muy estético, y también escasamente acorde con la ética democrática, lo usual y frecuente es hablar del "consenso"; palabra harto repetida que, sin duda, es loable y digno de resaltar. Pero, sea como fuere, lo cierto es que hicieron falta muchas cenas sin testigos para cerrar y llegar a esos acuerdos. No hay más que repasar las páginas de la prensa de aquellos dias para comprobar y anotar las constantes referencias a esas "cenas constitucionales" 51. Todo pareció cerrarse entre platos, cubiertos, postres y cafés, esto es, en reuniones sin tanta luz ni tanto taquígrafo. De ahí que

46 Pérez-Llorca, José Pedro, “¿Balance o liquidación?”, en España constitucional (1978-2018): Trayectorias y perspectivas, dir. Benigno Pendás, Esther González y Rafael Rubio (coords.), t. I., Centro de Estudios Politicos y Constitucionales, Madrid, 2018, pp. 58 y 59.

47 Charles T. Powell, España en democracia (1975-2000)... op. cit., p. 223.

48 Sobre el ambiente político de esos dias merece consultarse De Esteban, Jorge y López Guerra, Luis, "Las riendas del consenso", Cuadernos para el Dialogo, 3 de julio de 1978, p. 16 y de los mismos autores "La trampa del consenso", Cuadernos para el Dialogo, 27 de mayo de 19789, p. 21 .

49 Tomas Villarroya, Joaquín, "Proceso constituyente y nueva Constitución. Un análisis crítico", Revista de Estudios Politicos, núm. 10, 1979, p. 65.

50 Freixes San Juan, M ${ }^{a}$ T., “Crónica de una Constitución consensuada”, op. cit., p. 112.

51 A saber: "PNV. La última cena constitucional", Cuadernos para el Dialogo, 29 de julio de 1978, pp. 12 y ss. Elocuente artículo también, al menos, por su título el de Abascal Gasset, Federico, "La Constitución ya está 'cenada", Cuadernos para el Dialogo, de 17 de junio de 1978, pp. 18 y 19 donde ya se decía: "Los debates extraparlamentarios sobre el anteproyecto constitucional han dejado de ser materia reservada. Reservada se entiende, a un puñadito de legisladores que durante diez largos meses han elevado a regla el ocultismo (...) El asunto del consenso ya no es pues, arcano, recóndito, misterioso y secreto. Se sabe hasta el menú que servía el restaurante Nuevo Anselmo, sito en la calle del Conde de Xiquena, a las mini Cortes constituyentes que se reunió en el despacho del diputados socialista Peces-Barba, abierto en la misma calle" (p. 18). 
muchos ya en los propios debates constitucionales considerasen que el consenso era una especie de enjuague y pastel y que incluso se le considerase un manejo antidemocrático tendente a evitar los debates y a oscurecer la necesaria exigencia de luz y taquígrafos, según recuerda Peces-Barba ${ }^{52}$. En un sentido similar Alzaga considera que "durante el largo caminar de la Comisión de Asuntos constitucionales del Congreso, hubo de funcionar una especie de segunda Ponencia de facto y noctámbula que, integrada por parlamentarios de numerosos partidos, fue reformando muchas soluciones alcanzadas en la Ponencia y elaborando de común acuerdo multitud de enmiendas in voce que eran presentadas y votadas en las sesiones oficiales y diurnas de la Comisión"53. Así, hubo "abuso de enmiendas elaboradas sobre la marcha o fruto "de cuchicheos tras la cortina..., al margen de la luz, de los taquígrafos y de la prenda", obligando, se quejó López Rodó "a que nos pronunciásemos sobre estas enmiendas in voce, como digo, improvisadas en el acto, jugándonos así la Constitución a cara o cruz" 54 . No era muy estético, mucho menos ético, pero, quizás el único modo de superar el tremendo escollo. Ciertamente, "los retos politicos eran enormes y requerian de soluciones inteligentes, sí, pero también asociados a nuestros demonios domésticos: la definición de la forma de Estado/gobierno (monarquía o república), la cuestión religiosa, el modelo de distribución territorial del poder político, la consolidación de la un Estado de Derecho, el reconocimiento de un régimen de libertades (la cursiva es mía) y la incorporación al proyecto europeo"55. El caso es que, pesar de todo, el 21 de julio el Congreso de los Diputados lo aprobó por 258 votos a favor y, tan solo, 2 en contra ${ }^{56}$.

\section{B. Los derechos en el Anteproyecto de Constitución española,}

La cuestión es ¿qué pasó con el Título I que fue el principal motivo de conflicto nada más comenzar? De este concreto aspecto se sabe muy poco, a pesar de ser "parte más profunda e importante de la Constitución" en opinión de Peces- Barba, al incorporar los dos grandes valores del mundo moderno: la libertad y la igualdad; la verdadera médula de la Constitución (para el senador Escudero) ${ }^{57}$. Es aquí, pues, donde está el quid de la cuestión, pues, quizás, obedeció más a la necesidad de salvar los muebles que a un proyecto meditado y bien estructurado, al menos en lo que se refiere a su Título I. Tan solo encontramos algunas referencias tangenciales en las crónicas de la época o en los relatos posteriores. A veces ni tan siquiera eso. Expliquemos, pues, si quiera brevemente cómo se gestó, de verdad, el tan conflictivo, a la par que relevante,

52 Gregorio, Peces-Barba, La democracia en España. Experiencias y reflexiones, op. cit., p. 174.

53 Alzaga Villaamil, Óscar, La Constitución española de 1978 (Comentario sistemático), Madrid, 1978, ed. del Foro, p. 50

54 Cit. José María García Escudero y Asunción García Martínez, La Constitución día a día. Los grandes temas de la Constitución de 1978 en el debate parlamentario, op. cit., p. 25

55 González-Trevijano, Pedro, "La Constitución pintada", BOE/Real Academia de Jurisprudencia y Legislación de España, Madrid, 2018, p. 188.

56 La discusión del Dictamen de la Comisión se desarrolló del 4 al 21 de julio

57 José María García Escudero y Asunción García Martínez, La Constitución día a día. Los grandes temas de la Constitución de 1978 en el debate parlamentario, op. cit., p. 111 y 112. 
Título I, que a día de hoy sigue dando ciertos quebraderos de cabeza. Así, sin minusvalorar el tan manido "consenso" y su significado y su importante aportación para la redacción de la Constitución española, lo cierto es que, en el Título I gracias o, a pesar de los pactos, mucho de lo que inicialmente se consideró, fue desgraciadamente sacrificado.

Consultados los textos clásicos sobre el proceso de redacción de la Constitución española de 1978, debe señalarse que el 1 de agosto de 1977 tuvo lugar la primera reunión de la Ponencia, presidida por don Emilio Attard, en que Miguel Herrero y Rodríguez de Miñón "hizo una declaración general demasiado ambigua para ser útil, donde ya insinuó la idea de un texto breve centrado especialmente en la organización de poderes y donde no había una referencia precisa a los derechos humanos, sino a las garantias constitucionales. Herrero, expresó su idea de que no era necesario un catálogo de derechos en la Constitución, y que en todo caso era suficiente con una referencia al acatamiento por los poderes públicos de los textos internacionales de derechos humanos" 58 .

Recordemos, que en materia de derechos si bien Herrero de Miñón era partidario de una Constitución breve, centrada en la organización de poderes, sin que estimara necesario un largo catálogo de derechos, Peces-Barba defendia la necesidad de un texto más extenso, con una parte dogmática que constitucionalizara los derechos y libertades, así como su garantía efectiva ante los Tribunales. Mientras que Fraga se inclinó inicialmente por un conjunto de leyes constitucionales al estilo de las de la III República francesa (...) Tanto el ponente comunista, Solé Tura, como el de minoría catalana, Roca, se mostraron más cercanos al planteamiento de Peces-Barba, siendo esto el que al final se impuso"59. Así, en "Los Comunistas y la Constitución", Solé Tura publica la estructura constitucional que proponia el $\mathrm{PCE}^{60}$, que respecto del título relativo a los derechos comprendia tres capitulos por este orden: Derechos y garantias individuales y politicas, Sociedad, familia y Cultura, Derechos y garantias económico-sociales. Para estos, pareció obvio que "la nueva Constitución española hay que dotarla de verdadero contenido democrático, a través de la declaración explícita y con carácter de vigencia desde su formulación constitucional de los derechos humanos fundamentales, civiles, políticos, económicos, sociales y culturales (...) se recogen, con todos los efectos naturalmente derivados, los derechos a la vida y a la integridad personal, libertad personal y seguridad; derechos de igualdad entre las personas, de expresión e información, de conciencia y religión, de residencia y emigración, asociación, reunión y manifestación, así como los de participación en la vida pública. Entre los derechos económicos, sociales y culturales, los de trabajo, huelga y libertad sindical, derechos garantizados a una sanidad, educación, vivienda y calidad de vida dignas, enseñanza básica y media gratuita y acceso a la universidad o estudios superiores en igualdad de oportunidades. Estos derechos no se formularán como una mera declaración de principios programáticos sino que deberán establecerse al mismo tiempo, las garantías para su efectividad y su

58 Peces-Barba, Gregorio, La elaboración de la Constitución española de 1978, Centro de Estudios Constitucionales, Madrid, 1988, p. 34. 224.

59 Powell, Charles T., España en democracia (1975-2000), Plaza y Janés, Barcelona, 2001, p.

60 Solé Tura, Jordi, Los Comunistas y la Constitución, op. cit., pp. 26 y 35. 
vigencia legislativa, entendiéndose directamente aplicables con la consiguiente derogación de cuantas leyes o preceptos se opongan a los mismos", se afirman en "La izquierda y la Constitución" en abril de $1978^{61}$. A lo que se oponía Herrero por los peligros de la acumulación de contenidos heterogéneos, cuando no contradictorios ya por la vía de la mera superposición. No escondía, pues, su deseo de eliminar esa parte dogmática, lo que entendía que facilitaría el consenso ${ }^{62}$.

Pero más concretamente, el tema de los derechos fundamentales se debatió más en firme a partir del 1 de septiembre en que "se pasó a analizar la parte correspondiente al Título II y, tras un debate sobre el método de trabajo a seguir, los representantes del grupo de Alianza Popular, Socialista, y Comunista, hicieron una exposición general de los documentos que habian aportado, que fueron comentados por los demás miembros de la Ponencia. Terminada la exposición aludida, y tras, el anuncio por parte de los representantes de UCD de que el documento de su grupo adoptaba estaba reflejada en el texto de la Convención Europea de Derechos Humanos, sus Protocolos, y la Carta Social Europea (...) los representantes del grupo que habian hecho su exposición solicitaron de los demás la presentación de textos propios, y se acordó que el método de trabajo para la próxima reunión consistiría en la presentación y exposición por los demás grupos de su criterio sobre el Título II y en la adopción de un texto de los propuestos como documento de trabajo, sobre el cual se abriría el correspondiente debate" 63 . El día 6 de septiembre se continuó con el debate de lo relativo al contenido del Título correspondiente a los derechos fundamentales, continuando con la exposición del texto presentado por el Grupo Vasco-catalán, para pasar a la intervención del representante de UCD que presentó un escrito insistiendo en su postura sobre la referencia a los tratados internacionales en materia de derechos. No obstante, la Ponencia decidió "por mayoría y como método de trabajo utilizar el texto presentado por Alianza Popular y el del grupo Vasco-Catalán que sintetizaba algunos criterios de los otros grupos, sin perjuicio de las intervenciones de los otros miembros de la Ponencia a raíz de la discusión. Posteriormente se analizarian las materias contenidas en los restantes textos propuestos. Por otra parte, también se acordó que una vez determinado el contenido de los derechos fundamentales se analizaría el tema de las garantias"64. Recuerda Freixes que los trabajos se iniciaron a partir de las propuestas que cada uno de los asistentes a estas reuniones presentaron, por lo que "los textos no fueron conocidos en su conjunto sino por títulos. Los ponentes de los tres partidos, el PSOE, el PCE y AP, presentaron textos completos, el ponente de Minoría Catalana presentó otros la mayor parte de los cuales intentaban una sintesis o transacción, siento los representantes de UCD quienes

61 Jiménez Villarejo, Carlos, y Rodriguez-Aguilera, Cesareo, "Las garantias de los derechos humanos en el actual proceso constituyente", en VV.AA., La izquierda y la Constitución, ed. Taula de Canvi, 1978, pp. 76 y 77.

62 Herrero de Miñón, Miguel, "Falsas y verdaderas vías del consenso constitucional”, op. cit., p. 80 .

63 “Actas de la Ponencia constitucional”, Revista de las Cortes Generales, núm. 2, 1984, pp. 262 y 262.

64 Ibidem, p. 262. 
fueron un tanto a remolque de las propuestas de los demás partidos"65. Sus propuestas escritas fueron menores y sus intervenciones no siempre estuvieron coordinadas, si bien, respondian a las intenciones del Gobierno. Mientras que en el caso del PSOE admite el propio Peces-Barba que "para los derechos fundamentales nos basamos en el Estatuto de Libertades Públicas, que yo redacté y que se aprobó en el XXVII Congreso de diciembre de 1976"66.

Por tanto, al menos, en lo estructural, no se apartaba mucho del borrador o bases constitucionales del profesor de Esteban, pues ambos documentos contenían un listado de derechos y un epígrafe aparte con las garantias que deberian corresponderle.

Es por tanto, el 6 de septiembre cuando definitivamente se acuerda que definitivamente la Constitución de 1978 tendría una parte dogmática y el 8 de septiembre empiezan a analizar el contenido concreto de cada uno de los derechos. Como curiosidad el acta/minuta de esta fecha señala: "(Informática, pendiente de redacción") ${ }^{67}$. Debate que continúa los 15 de septiembre y 27 respecto de las garantías en que se aprueba la redacción del entonces artículo 44, bien diferente a la actual. Si bien, en opinión de Peces-Barba "cuando se discutian los artículos iniciales del Título I sobre los derechos humanos, se intentaron recortar algunas medidas protectoras de la libertad personal", incidente que precipitó la crisis por la que tuvieron que intervenir Abril Martorell y Guerra68. Comenzaron las cenas: "la reunión clave a instancias de Abril, se produjo en una cena en el restaurante José Luis, enfrente del Santiago Bernabeu (...) Alli se sentaron las bases de los cambios necesarios para nuestra incorporación al consenso"69.

65 Freixes San Juan, M ${ }^{\mathrm{a}}$ T., “Crónica de una Constitución consensuada”, op. cit., pp. 106 y 107. Recuerda Freixes que "Únicamente han sido publicadas las propuestas llevadas a la Ponencia por el Grupo Parlamentario Comunista, debiendo inferirse las posturas programáticas de los mismos de la documentación extraparlamentaria, como son declaraciones a la prensa, programas elaborados en los Congresos de los partidos etc." (Ibidem, p. 107). Hoy, sin embargo, conocemos también la propuesta en que se basó la postura del PSOE elaborada por el profesor Jorge de Esteban (vid. nota 32).

66 Peces-Barba, Gregorio, La democracia en España. Experiencias y reflexiones, op. cit., p. 171. El texto integro y fidedigno del referido Estatuto de libertades en: Folleto "Programa de transición", Estatuto de Libertades Públicas, XXVII Congreso PSOE, Fondo de Documentación Jurídica del Centro de Estudios Políticos y Constitucionales. Una mera referencia al mismo en el Diario Arriba, de 17 de agosto de 1977: "Se ha estudiado, asimismo lo relacionado con los Derechos Fundamentales -prosiguió el señor Peces Barba- y sea producido un acuerdo sobre el tema. En este sentido, llevarán en su anteproyecto de constitución el estatuto de Libertades Públicas, para que sea recogido íntegramente en la Constitución. Los Derechos Fundamentales debían integrarse en la Constitución, los cuales debian recoger todas la libertades individuales en el plano económico, cultural, social, etc." (URL: https:/ / recursos.march.es/linz/I13660.pdf\#Search=estatuto\%20de\%20libertades\%20publicas).

67 “Actas de la Ponencia constitucional”, op. cit., p. 268.

68 Gregorio, Peces-Barba, La democracia en España. Experiencias y reflexiones, op, cit., pp. 185 y 186 .

69 Ibidem, p. 186. 
Tras la publicación de los trabajos de la Ponencia en noviembre ${ }^{70}$, las sesiones se vuelven a retomar el 6 de marzo de 1978 con el conflictivo tema del derecho a la educación, en que Peces-Barba abandona la Ponencia, que da por concluida su misión el 15 de marzo con su "Borrador del Proyecto de Constitución" en que el inintitulado Título II ofrece una serie de derechos sin ningún tipo de división o subdivisión interna.

En el fondo, el motivo de mayor desencuentro fueron los derechos sociales tal y como demuestra la evolución posterior y los cambios de sistemática que sufrió en varias ocasiones el Título I en la discusión posterior. Esta es la clave de la estructura del Título I y de sus significativo desorden y algunas carencias en materia de derechos sociales. Como afirma Alzaga, el consenso tenía la ventaja de que "facilitaría la elasticidad de la Constitución, y, de modo más natural, marginaría las fórmulas que la pudieron hacer más inelástica, lo que posibilitaría su vigencia duradera en el tiempo"71. Si bien, no a cualquier precio, que es lo que pasó con el Título I. Añade Powell que "la postura de Peces-Barba habría de marcar decisivamente el proceso constituyente, resultando el título primero de la Constitución dedicado a los derechos y deberes fundamentales, uno de los más controvertidos"72. Controversia que ha sido analizada frecuentemente en cuanto al contenido concreto de los artículos que recoge, obviando cualquier comentario del porqué de su definitiva estructura. Como certeramente señala Sebastián Martín, si bien es cierto que no se dieron demasiadas alteraciones entre la redacción del Anteproyecto, el Informe de la Ponencia y el texto final de la Constitución en relación con los derechos que aparecian en su Texto, estos se distribuian entre los entonces Título II ("Derechos y deberes fundamentales") y VII (Economía y Hacienda), lo que a juicio de Herrero de Miñón hipertrofiaba el texto de 197873 . Es más, apunta Serrano Alberca que "una vez redactados todos los artículos la ponencia se reunió para su ordenación en la forma que figura en el seno del Anteproyecto publicado, si bien dado que los acuerdos se resumían en la ordenación, no hubo acta o minuta de estas reuniones"74.

El caso es que el 17 de abril, concluido el estudio de las enmiendas presentadas al Anteproyecto de Constitución, en lo relativo a las "Enmiendas de carácter general" o la "modificaciones de orden sistemático, "la Ponencia, por mayoría y de acuerdo con la idea contenida en la enmienda número 779 del Grupo de Unión de Centro Democrático, realiza una nueva ordenación del Título II, que pasa a ser ahora el Título I con la rúbrica "De los derechos y deberes fundamentales". Este Título constará de un artículo introductorio, el art. 13 del texto del anteproyecto, que ha pasado a ser el art. 10; y de cinco capítulos, cuya

70 El primer texto fue filtrado a la prensa por el diputado socialista Pablo Castellanos en noviembre de 1977, viendo la luz en el número de 5 de enero de 1978 de la revista Cuadernos para el Dialogo (Cuadernos para el Dialogo, 22 de noviembre de 1977, Pablo Castellano, "Yo sí me acuerdo", pp. 141 y 142.).

71 Alzaga Villaamil, Óscar, Derecho Politico español, 1997, Ed. Centro de Estudios Ramón Areces, p. 143.

72 Powell, Charles T., España en democracia (1975-2000), op. cit., p. 225.

73 Miguel Herrero de Miñón, "Falsas y verdaderas vías del consenso constitucional”, op. cit., p. 92.

74 Serrano Alberca, José Manuel, “Actas de la Ponencia constitucional”, Revista de las Cortes Generales, núm, 1, 1984, p. 252. 
ordenación se irá analizando conforme se vayan estudiando los correspondientes artículos"75. Es en este momento cuando el Capítulo II pasa "a denominarse "De los derechos y libertades" y se divide en dos secciones: la primera tiene como rúbrica "De las libertades públicas"; y la segunda "De los derechos y deberes de los ciudadanos". Esta división en secciones se aprueba por mayoría con el voto en contra del representante del Grupo de Alianza Popular. En esta nueva ordenación se ha tenido en cuenta la enmienda $\mathrm{n}^{\circ} 779$ del Grupo de Unión de Centro Democrático, habiendo sido aceptada la enmienda $n^{\circ} 332$ del Grupo Socialistas del Congreso"76, según reza el Diario de Sesiones de dicha fecha77, que básicamente pretendia "una mejora en la colocación de los artículos de este capítulo, que los ordena u agrupa sistemáticamente teniendo en cuenta las materias de que tratan ${ }^{78}$. Sin embargo, la 779 si que era de mayor enjundia pues, además de proponer una enmienda a la denominación del entonces Título I por Preliminar, añadía la propuesta de "Enmienda y sistemática del Título II", que proponía su división en 6 capítulos:

$1^{\circ}$. De los españoles y extranjeros.

$2^{\circ}$. De las libertades públicas.

$3^{\circ}$. De los derechos y deberes de los ciudadanos.

$4^{\circ}$. De los principios rectores de la política económica y social.

$5^{\circ}$. De las garantias de las libertades y derechos fundamentales.

$6^{\circ}$. De la suspensión de las libertades y derechos fundamentales.

Añade: "El capítulo $1^{\circ}$ debe comprender el contenido de los artículos $11 \mathrm{y}$ 12. Con la redacción que proceda según las enmiendas siguientes.

El capítulo $2^{\circ}$ debe contener en la redacción que definitivamente proceda los artículos 14, 15, 16, 17, 18 (párrafos 1, 2, y 3), 19, 20 (párrafos 1, 3 y 4, 6 y 7), 21, 22, 23, 24 (párrafos 1, 2 y 3).

El capítulo $3^{\circ}$ debe contener en la redacción que debidamente proceda los artículos 25, 26, 27, 28, 29, 30, 31-2, 31-3 у 32 .

El capítulo 41 debe contener en la redacción que debidamente proceda los artículos contenidos en el capítulo $3^{\circ}$ del título II, más la redacción que definitivamente proceda del artículo 120 del Anteproyecto enmendado" 79 .

Sin mayor justificación, salvo por lo que señalaba de "revisión de concordancias con el art. 47 tanto respecto de la numeración de los artículos como respecto de los estados previstos en el art. 94"80. Ahora bien respecto del

75 Cortes Generales, Trabajos parlamentarios. Constitución española, Boletín Oficial de Cortes, de 17 de abril de 1978, núm. 82, p. 1527.

76 Esta proponía la modificación del articulado del Capítulo II del Título II del anteproyecto de Constitución para garantizar la "mejora en la colocación de los artículos de esta capitulo, que los ordena y agrupa sistemáticamente teniendo en cuenta las materias de que tratan" (Cortes Generales, Trabajos parlamentarios. Constitución española, op. cit., t. I, p. 274)

77 Cortes Generales, Trabajos parlamentarios. Constitución española, t. I., op. cit., p. 1529.

78 Ibidem, p. 274.

79 Ibidem, pp. 483 y ss.

80 Ibidem. 
entonces art. 45, que regulaba las garantías de los derechos proponía la siguiente redacción: " 1 . Los derechos y libertades reconocidos en los capítulos $2^{\circ}$ y $3^{\circ}$ del presente título vinculan a todos los poderes públicos. Solo por Ley, que en todo caso deberá respetar su contenido esencial, podrá regularse el ejercicio de tales derechos y libertades, establecer limites a los mismos por motivos de seguridad, salud, moral pública y excluir o limitar el ejercicio de determinadas libertades para ciertas categorias de servidores públicos [...]

3. La tutela de los derechos reconocidos en el capítulo $3^{\circ}$ de este título procederá a través del recurso de inconstitucionalidad previsto en el art. 152, a), de la Constitución y, en todo caso, ante la jurisdicción ordinaria, mediante los procedimientos establecidos en las leyes que los desarrollan.

4. Los principios reconocidos en el capítulo $4^{\circ}$ de este título inspirarán la actuación de los poderes públicos y en especial la legislación, pero no generan derechos subjetivos ni dan lugar a pretensión alguna ante los Tribunales"81.

Como se puede observar a vuela pluma, para aquel entonces las lineas maestras del sistema de protección de los derechos y libertades de la Constitución española de 1978 ya estaban trazados, a pesar de alguna modificación y ajuste posterior, al establecer ya una redacción que "se ajusta más a la sistemática correcta del título $2^{\circ}$, distinguiendo claramente las libertades tutelables a través del recurso de amparo, los derechos protegidos por la jurisdicción ordinaria en la medida en que son incorporados a la legislación y por el Tribunal Constitucional frente a la acción del propio legislador y los principios rectores cuya función inspiradora no puede perturbar la imparcialidad de los Tribunales mediante una coloración tutitiva de la justicia", según reza la justificación de la enmienda 779 para este precepto ${ }^{82}$.

Es este el momento en que aparece la expresión: "principios rectores de la política económica y social", seguido de otro en que se establecian las "garantías de los derechos fundamentales". Es ahí donde seguía la clave del desacuerdo ${ }^{83}$; en las garantías que corresponderian a cada tipo.

Ciertamente, el texto que aprobó el Congreso de los Diputados reflejaba la heterogeneidad ideológica de la Ponencia, o acaso de difícil acuerdo en posiciones tan dispares; heterogeneidad que no solo afectaba a la concreta redacción de los artículos contenidos en el Título I como el 15, el 16 ó el 27, sino en cómo se entendieron y presentaron los derechos sociales, visiblemente minusvalorados y recortados. Así lo demuestra el Capitulo III, donde se recogieron los que inicialmente eran y fueron considerados derechos sociales. Otra vez se respiraba en el ambiente la sobre de la duda sobre esas "reuniones informales y extraparlamentarias no pocas de ellas nocturnas de las que no hay constancia ni transcripción ${ }^{84}$. Y así, difícil es saber qué pasó.

Como ya anticipábamos, en junio de 1978, la Comisión de Asuntos Constitucionales y Libertades Públicas, una vez examinado y enmendado el

81 Ibidem, p. 489.

82 Ibidem, pp. 489 y 490.

83 Sebastián Martín, “Derechos sociales y procesos constituyentes (1931, 1978 ¿2016?)”, op. cit., p. 64.

84 Pedro González-Trevijano, La Constitución pintada, op. cit., p. 200. 
Anteproyecto, publicaba su Dictamen y, por arte de birlibirloque, en el Capítulo II aparece ya con carácter casi definitivo esa Sección $1^{\text {a }}$ "De las libertades públicas" y otra Sección $2^{\text {a }}$ "De los derechos y deberes de los ciudadanos" y un Capítulo III "De los principios rectores de las política social y económica", como consecuencia de la aceptación de la aludida enmienda 779 que nada hablaba de dos secciones en el Capítulo II. Así reza el Boletín Oficial de las Cortes, de 17 de abril de $1978^{85}$ entre las "Enmiendas de carácter general" en que la Ponencia analizó las propuestas de redacción de un preámbulo y las "modificaciones de orden sistemático", que "por mayoría y de acuerdo con la idea contenida en la enmienda número 779 del Grupo de Unión de Centro Democrático, realiza una nueva ordenación del Título II, que pasa a ser ahora el Título I con la rúbrica "De los derechos y deberes fundamentales". Este Título consta de un artículo introductorio, el art. 13 del texto de anteproyecto, que ha pasado a ser el art. $1^{\circ}$; y de cinco Capítulos, cuya ordenación se irá analizando conforme se vayan estudiando los correspondientes artículos [...]

CAPITULO SEGUNDO: De las libertades públicas. Este Capítulo ha pasado a denominarse "De los derechos y libertades" y se divide en dos secciones: la primera tiene como rúbrica: "De las libertades públicas"; y la segunda "De los derechos y deberes de los ciudadanos". Esta división en secciones se aprueba por mayoría con el voto en contra del representante del Grupo de Alianza Popular. En esta nueva ordenación se ha tenido en cuenta la enmienda 779 del Grupo de Unión de Centro Democrático, habiendo sido aceptada la enmienda $n^{\circ} 332$ del Grupo Socialista del Congreso" 86.

\section{Los "Principios rectores de la politica social y económica",}

Por tanto, esta sistemática, unida a la definitiva redacción del art. 53 de pareja evolución constituyente, terminó por conformar un modelo de derechos fundamentales y libertades públicas escasamente ambicioso para una de las Constitución más modernas de Europa de aquel entonces. El entonces artículo 45 y después 48 (actual 53) es el que explica, en parte, la ulterior división en secciones del Capítulo II y tipos de derechos, por ende, que ya por entonces entendia la tutela jurisdiccional y el amparo como garantía de primer grado que protegió también a la igualdad y no discriminación y a los derechos y libertades reconocidos en la Sección Primera donde se incluyó la huelga y la libertad sindical, pero no el derecho al trabajo y las disposiciones sobre negociación y convenios colectivos ${ }^{87}$. Mientras que los que se llevaron al Capítulo III fueron matizadísimos en sus garantias de reconocimiento y materialización efectiva dejándolos en un "ya veremos" en función de un posible (o no) desarrollo legal futuro. En UCD mientras no generasen auténticos "derechos" respiraban tranquilos. Es más Raúl Morodo presentó una enmienda para que el amparo ante

85 Cortes Generales, Trabajos parlamentarios. Constitución española, Boletín Oficial de Cortes, sesión de 17 de abril de 1978, t. I, núm, 82, op. cit., pp. 1520 y ss. En concreto las 1527 a 1530.

86 Ibidem, pp. 1527 y 1529.

87 Sebastián Martín, “Derechos sociales y procesos constituyentes (1931, 1978 ¿2016?)”, op. cit., p. 65. 
el Tribunal Constitucional se refiriese a "todos los derechos reconocidos en la Constitución" pero el PNV pidió que se suprimiera ${ }^{88}$.

El caso es que el artículo 53 en la redacción que hoy conocemos, fue aprobado en la Comisión constitucional por 31 votos a favor, sin mayor debate, ni votos en contra. Lo que induce a pensar que las posiciones estaban fijadas previamente, aunque la jerarquización de derechos que perpetuaba no fuese coherente con el "pasticio" (si se me permite esta expresión italiana) en que quedó convertido el Título I, donde nada se corresponde con cómo se hace llamar. Como certeramente ya señalaba Hernández Gil "Comparando el contenido del Capítulo tercero con el del Capítulo segundo - "derechos y deberes de los ciudadanos"- se aprecia que la distribución de los respectivos contenidos se resienten de cierto convencionalismo carente de rigor sistemático"89. Así en el Capítulo segundo del Anteproyecto ya se encuentra un contenido que no solo son libertades públicas y en el tercero bajo la denominación de "principios rectores y derechos económicos y sociales" se incluyen más bien derechos proclamados en forma de principio ${ }^{90}$.

Vienen, pues, como anillo al dedo las palabras de Manuel Fraga, en la sesión de 16 de mayo de 1978 de la Comisión de Asuntos Constitucionales y Libertades Públicas que decía como "las Constituciones acusan mucho más todavía el famoso juego de las siete y media, el quedarse o el pasarse"91. En cuanto a los derechos fundamentales la Constitución de 29 de diciembre de 1978 se quedó y no se pasó, acogiéndo a una concepción quizás demasiado conservadora y, en absoluto, pensada para la evolución y desarrollo que supondría el paso del tiempo.

Así, si los derechos valen lo que valen sus garantías, el artículo 53 ya se encargó de que su valor se viese considerablemente rebajado, pues el Estado ya no estaba ante la obligación de afrontar la causa de los desequilibrios económicos y sociales, pues los derechos sociales, al margen de la huelga, la sindicación y la regulación de las condiciones de trabajo y a la negociación colectiva, aquellos, que, de verdad, habrian concertado el Título I con el Preámbulo quedaron rebajados a su consideración de mero "principio rector". Así lo afirmaba Herrero de Miñón por aquellas fechas, que bien claro tenía que "los principios rectores, tal y como aparecen en la Constitución española de 1978 (Título I, Capítulo $3^{\circ}$ ) se insertan en una tradición muy defectuosa iniciado en el texto de 1931, definitivamente acuñado en la Constitución irlandesa de 1937, y se difundió en la Lejano Oriente a partir de la birmana de 1948 y la hindú de 1950. Se trata, en síntesis, de unos valores que deben inspirar al legislador, a la Administración, e incluso al juez pero no pueden ser alegados ante los Tribunales para impugnar la constitucionalidad de una norma ni para pedir la tutela de un derecho", afirmaba

88 Ibidem, p. 66.

89 Hernández Gil, Antonio, Obras completas, t. VII: "La Constitución y su entorno", ed. Espasa Calpe, Madrid, 1989, p. 350.

${ }^{90}$ Hernández Gil, Antonio, Obras completas, t. VII: "La Constitución y su entorno": "Estudios sobre el Anteproyecto de Constitución”, ed. Espasa Calpe, Madrid, 1989, pp. 367 y 382.

91 Cortes Generales, Trabajos parlamentarios. Constitución española, op. cit., t. I., p. 877. 
taxativamente Herrero en la Comisión constitucional ${ }^{92}$. Quedaban, en su opinión, reducidos a meras declaraciones, a lo sumo con alcance programático e indicativo ${ }^{93}$. Es decir, un valor sin valor, si se me permite el juego de palabras. Ya que no se pudo aligerar el texto constitucional de una serie de afirmaciones, a juicio de Herrero de Miñón, poco operativas ${ }^{94}$, se imponía rebajar la ambigüedad y retórica, negando carácter normativo a determinadas partes, id est, al Capítulo III del Título I, al distinguir entre "derechos" y meros "principios rectores", entre norma y mera emotividad. Quedaban, pues, reducidos a orientar o regir la política del Gobierno, pero de aquí a hablar de una obligación en firme... esto es, de corrección en profundidad del sistema económico para tender a la eliminación de las desigualdades sociales había un paso más que no se dio en 1978. Lo que contrasta con la opinión de López Pina que defiende que "con los principios rectores el constituyente quiso acotar un espacio de política constitucional al abrigo de todo decisionismo, en el que sea posible el ejercicio de la segura e igual libertad sin dependencias ajenas a la voluntad de los ciudadanos [...] los principios rectores son núcleo de cuanto los españoles identifican como la Constitución como patrimonio público propio"95.

Como recuerdan Gallego-Díaz y De la Cuadra96, el tema del Título primero "se configuró inmediatamente como una batalla UCD-PSOE en la que cada partido luchaba casa por casa y piso por piso". Así, a pesar de la insistencia de las posiciones socialistas en la presencia de un título propio sobre derechos humanos, la regulación de estos ya, desde el principio, nació tocada y bajo mínimos, pues, en opinión de Peces-Barba sobre este tema se inició una animada discusión que consiguió, al menos, el inicial acuerdo de regular los derechos de la Constitución española. Si bien, no con una regulación muy ambiciosa ${ }^{97}$, pues los temas de derechos fundamentales se incluirian en el primer título, según la propuesta del ponente de minoría catalana, a modo de cajón de sastre, donde incluiría todo lo que no fuese parte orgánica ${ }^{98}$. Así, en reunión de 1 de septiembre se abordó el estudio de la parte relativa a los derechos fundamentales, que se completaron los días 6, 8, 15 y 27 del mismo mes. Unas fechas en que la atención se centró en superar las reticencias de incluir una regulación de derechos, ofreciendo un Capitulo ordenado y coherente frente "al caos de artículos aprobados sin esquema racional ni distribución por capitulos"99; labor que se termina el 5 de enero en un inicial Capitulo II y un Capitulo III con las

92 Cortes Generales, Trabajos parlamentarios. Constitución española, Diario de Sesiones del Congreso, de 5 de mayo de 1978, núm. 59, op. cit., p. 2026. 93.

93 Miguel Herrero de Miñón, "Falsas y verdaderas vías del consenso constitucional”, op. cit., p.

94 Ibidem, p. 93.

95 López Pina, Antonio, "Los principios rectores de la política social y económica", en Comentarios a la Constitución española de 1978, dir. Óscar Alzaga Villaamil, t. IV, Cortes Generales/Editorial de Derecho Reunidas, 1996, pp. 22 y 24.

96 Gallego-Díaz, Soledad y De la Cuadra, Bonifacio, Crónica secreta de la Constitución, Tecnos, Madrid, 1989, p. 53.

97 Ibidem, pp. 53 y 55.

98 Gregorio, Peces-Barba, La elaboración de la Constitución española de 1978, op. cit., p.37.

99 Ibidem, pp. 56 y 57. 
instituciones ya señaladas que, a juicio de Peces Barba, era más adecuado entonces ${ }^{100}$. Fue, después, cuando se procedió a la división en secciones, pero no se acierta a explicar muy bien cuál fue ni motivo ni el origen. Solo se apunta que el clima de tensión fue en aumento a medida que se avanzaba en la discusión constituyente. De ahí que se optase por resguardar todo lo trabajado por un mayor secretismo que el inicial. Así, todo lo que se hizo y acordó después es difícil de saber.

Lamentablemente, los textos consultados se dedican a intentar explicar cómo se desarrollaron las negociaciones y acuerdos sobre el texto concreto de cada uno de los artículos, pero nadie explica cómo se acordó el cambio de sistemática. Lo más cercano a intentar ofrecer una explicación, es que el día 22 de mayo de 1978 en una cena secreta entre Pérez Llorca, Guerra, Peces Barba. Enrique Múgica, Abril Martorell, Gabriel Cisneros y Arias Salgado en el restaurante José Luis se decidió discutir globalmente los artículos comprendidos entre el 26 y el 50, es decir, parte de los inicialmente comprendidos en el grupo de libertades individuales y todos los de Capítulo III de "Principios rectores y derechos sociales y económicos, incluso los primeros artículos sobre la Corona ${ }^{101}$. En definitiva, que, en realidad, el Dictamen de la Comisión constitucional sobre Asuntos Constitucionales y Libertades Públicas no fue obra de esta, pues el propio Abril Martorell anunciaba a Sole Tura y Miquel Roca que "las negociaciones al margen de la Comisión se reanudarian cuanto antes, a fin de acelerar los debate y llegar a un acuerdo sobre la Constitución en su totalidad"102. Continua, pues, el secreto sobre esta cuestión. Si bien, nos induce a una primera conclusión: en el Capítulo III del Título I hay verdaderos derechos sociales porque así lo quiso el constituyente. Esto es indudable en el caso de la salud, la vivienda y el medio ambiente, pero también en otros casos como los derechos de los consumidores o de los menores, pues, como recuerda López Pina estos derechos "vienen a ser extensiones del constituyente de los derechos fundamentales condensados en el postulado del Estado social"103.

El paso del texto por el Senado no supuso cambio alguno. Es más, en esta Cámara todo discurriría bajo la ley implacable de la aritmética: "los 85 senadores dispersos en los pequeños grupos deberán someterse al bloque de los 162 socialistas y ucederos. Las modificaciones al texto aprobado por la Cámara Baja serán obviamente escasas y se limitarán a ciertos retoques gramaticales. E1 Senador-académico Cela ha sugerida varias (...) Modificaciones de fondo, una vez sondeados los distintos grupos parlamentarios parece que solo se realizarán en el terreno de las competencias del Senado"104. En definitiva, se pretendía trasladar el consenso conseguido entre UCD y PSOE del Congreso al Senado y que los debates en la Cámara Alta no se extendiesen ad infinitum. En pocas palabras,

\footnotetext{
100 Ibidem, p. 56.

101 Soledad Gallego-Díaz y Bonifacio de la Cuadra, Crónica secreta de la Constitución, pp. 61.

102 Ibidem, pp. 62.

103 Antonio López Pina, Antonio, "Los principios rectores de la política social y económica", op. cit., p. 33.

104 Abascal Gasset, Federico, Gallego-Díaz, Sol y Martínez, José Luis, "A la sombra de la Guillotina", Cuadernos para el Diálogo, 12 de agosto de 1978, p. 16
} 
"afilar el arma de la guillotina para decapitar las pérdidas de tiempo. Mediante la guillotina se somete a votación una enmienda inmediatamente después de que haya sido defendida por su patrocinador. Sin más debate (...) no se producirán, pues, escaramuzas estrictamente politicas durante los debates, ya que el frente consensual UCD-PSOE ha adoptado meditas para evitarlas (...) Aunque los debates están atados, por UCD y PSOE, y bien atados los acuerdos con la cuerda floja del consenso"105.

Los malos augurios de Jorge de Esteban y Luis López Guerra parecieron reconducirse pues explicaban cómo surgió la duda en el Senado, habida cuenta de algunos indicios que hacian presumir que cierto sector de la segunda Cámara estarian dispuestos a correr el riesgo de poner patas arriba todo lo acordado. Como sostienen "fue un error innegable concebir un proceso constituyente basado en dos Cámaras, porque, por una parte, se duplica un proceso que en sí es complicado y lento y, por otra, puede hacer peligrar el mantenimiento del consenso que, se quiera o no está prendido con alfileres, aunque obviamente, haber conseguido tal circunstancia ya es alago insólito en la historia constitucional española"106.

Por desgracia, con cierto lamento triste, el consenso ayudó poco en la comprensión y desarrollo constitucional de los derechos fundamentales. No se trata de sumarnos, sin más, a las afiladas y demoledoras críticas de todo lo que se consiguió con el consenso, que fue mucho y muy loable en otras partes de la Constitución. No así en el Título I, cuyo resultado final se asemeja al de una especie de selva intrincaba e infranqueable llena de desorden obra del corte, del recorte y de la recolocación sin orden ni concierto, que (ya lo hemos dicho) casa muy mal con el Preámbulo que a modo de añadido de última hora, que se unió después, otra vez, sin ton ni son.

Por expresivas, reproducimos las palabras de Joaquín Tomás Villarroya "la sistemática de la Constitución dista también mucho de ser perfecta. Los defectos que podrian señalarse son numerosos"107. Así, "El Título I, relativo a los derechos y deberes fundamentales es sumamente amplio; el orden en la relación de derechos y libertades consagrados es frecuentemente insatisfactorio; determinados preceptos regulan unos y otras de manera deshilvanada; y, pese a aquellas extensión, quedan todavía fuera del título I, dispersos a lo largo del texto constitucional, la audiencia de los ciudadanos, el acceso de estos a los archivos y registros administrativos, el derecho a ser indemnizado por toda lesión que sufran en sus bienes por razón del funcionamiento de los servicios públicos y el derecho a la indemnización por los errores judiciales"108. Si a esto sumamos su escasa correspondencia con una hipotética "Teoria de las generaciones de derechos" no queda más que aceptar que este título, en algunas ocasiones adolece del "sindrome de Frankestein", pues, por un lado, abundan los "falsos universales concretos", cuyo prototipo son las atribuciones a determinados colectivos -jóvenes, niños, ancianos- de derechos y obligaciones reconocidos,

105 Ibidem, pp. 16-17.

106 Jorge De Esteban y Luis ópez Guerra, “En defensa de la Constitución”, op. cit., p. 17.

107 Joaquín Tomas Villarroya, "Proceso constituyente y nueva Constitución. Un análisis crítico", op. cit., p. 71 .

108 Ibidem, p. 72. 
cuando estos son predicables, en realidad, de cualquier ciudadano"109. Y, por otro, dicho consenso se circunscribió a la determinación del contenido de aquellos derechos sobre las que las posiciones se manifestaban con un preocupante encono. A saber: el derecho a la vida, la educación etc.

Poco refleja, pues, de verdadera reflexión serena sobre su sistemática. De ahí, que todo apunte más a "lo insostenible de una tesis muy extendida durante los últimos años en España, conforme a la cual una Constitución debe nacer del consenso [...] Se trata de una concepción del consenso constitucional indefendible en el plano teórico y aún más frágil en el terreno de la realidad"110. En realidad, este Título es el máximo exponente de algunas de las antinomias técnico-jurídicas y de las ambigüedades y errores técnicos de que adolece el Texto de 1978. Es más, aunque es un primer momento lo pareciese, en realidad, no se dio con una solución aceptable de la inicial dificultad. Es más Sebastián Martín lo califica de "diálogo de sordos"111.

Recordemos, además, los objetivos del Preámbulo, junto con la afirmación del artículo I de que "España es una Estado social": "Garantizar la convivencia democrática dentro de la Constitución y de las leyes conforme a un orden económico y social justo (...) Promover el progreso de la cultura y de la economía para asegurar a todos una digna calidad de vida". La ausencia de concordancia se debe, como ya hemos dicho a una especie de política de partes en la redacción de nuestra Norma Fundamental. Lo curioso es que en el proceso constituyente todos parecian estar a favor de que se le denominase "Estado social y democrático", incluso los conservadores como José Miguel Ortí Bordás, vicesecretario general del Movimiento, creía que era un acierto porque el "Estado liberal de derecho" era un Estado en crisis al igual que Miguel Herrero de Miñón que consideraba que era "una consecuencia ineludible del Estado de Derecho a la altura de [aquellos] tiempos", pues venía a significar que el Estado no solo protege la libertad sino que facilita las condiciones que hacen posible su goce efectivo, como indicaría el artículo 9 de la Ley Fundamental y sus "principios rectores" 112 . Ahora bien, Herrero advertía que estas garantias y dichos principios solo podian constituir "unos valores que deben inspirar al legislador", no alegables "antes los tribunales para impugnar la constitucionalidad de una norma ni para pedir la tutela de un derecho. Por eso su "pretensión de validez" era, sin duda, "inferior a la de otros sectores de la Constitución"113.

Hubo acuerdo, parece, pero acuerdo sobre el que poco o nada ha quedado negro sobre blanco, por no hablar de un resultado final, cuanto menos, mejorable, pues los conservadores se opusieron a cualquier declaración de principios que pudiese contar con efectos jurídicos tangibles. De ello, es ejemplo, 87.

109 Miguel Herrero de Miñón, "Falsas y verdaderas vías del consenso constitucional", op. cit., p.

110 Óscar Alzaga, Del consenso constituyente al conflicto permanente, op. cit., p. 11.

111 Sebastián Martín, "Derechos sociales y procesos constituyentes (1931, 1978 ¿2016?)”, op. cit., p. 61.

112 Ibídem, p. 59. En concreto, las palabras de Herrero de Miñón en: Cortes Generales, Trabajos Parlamentarios, op. cit., t. I., pp. 638-640.

113 Sebastián Martín, "Derechos sociales y procesos constituyentes (1931, 1978 ¿2016?)”, op. cit., p. 62. 
V. gr. el debate de la Comisión de Asuntos Constitucionales y la redacción del artículo 9.2 por lo que tenía de desarrollo del carácter social del Texto del 78114 . Si extrapolamos este a los artículos contenidos en el Capítulo III podemos llegar a la conclusión de que la controversia se resolvió manteniéndolos en el terreno poco vinculante de los mandatos axiológicos al legislador ${ }^{115}$. Es más, inicialmente "apelaba a la irretroactividad de las normas restrictivas de los derechos individuales y sociales, pero el diputado de UCD, José Luis Meilán Gil, a la sazón Catedrático de Derecho Administrativo, afirmó desconocer cuál era el alcance de una norma restrictiva de derechos sociales. Quizás intuía el peligro de constreñir demasiado al legislador ${ }^{116}$. De ahí que el nuevo intento de que los derechos sociales gozasen de mayores garantías volviese a fracasar. No se consiguió tampoco su tutela directa ante los tribunales de justicia y la Ponencia acordó por "una mayoría amplia, en palabras de su portavoz J. pedro Pérez Llorca suprimirla también"117.

\section{CONCLUSIONES:}

Pero tanto consenso y tanta cena no fueron capaces de resolverlo todo. Como tampoco pudieron ofrecer una regulación ambiciosa y más contemporánea de los derechos fundamentales. "El mal consenso -como lo califico Sánchez Agesta-, que no resuelve y simplemente aplaza"118, pues "una vez más el pretendido consenso se obtiene optando "no ya sobre la ideas y los principios, y sobre sus deducciones y consecuencias, sino exclusivamente sobre palabras"119. En las "palabras" utilizadas podría estar la clave, pues ellas permiten el rastreo teleológico y ontológico del precepto o parte de la Constitución en que se incluya y de que se trate. Recuérdese que en el Capítulo III del Título I, al menos, en tres ocasiones se "cuela" la palabra "derecho" al referirse a la salud, la vivienda y el medio ambiente.

\section{BIBLIOGRAFIA:}

“Actas de la Ponencia”, Revista de las Cortes Generales núm. 2 de 1984.

"PNV. La última cena constitucional", Cuadernos para el Dialogo, 29 de julio de 1978.

Alessandro Pizzorusso, "Las "generaciones" de derechos", Anuario iberoamericano de justicia constitucional, No. 5, 2002.

114 Sebastián Martín, "Derechos sociales y procesos constituyentes (1931, 1978 ¿2016?)", op. cit., pp. 61 y 62.

115 Ibidem, p. 62.

116 Ibidem.

117 Ibidem.

118 Jose María García Escudero y Asunción García Martínez, Asunción, La Constitución día a día. Los grandes temas de la Constitución de 1978 en el debate parlamentario, op. cit., p. 28. 89.

119 Miguel, Herrero de Miñón, "Falsas y verdaderas vías del consenso constitucional”, op. cit., p. 
Antonio Hernández Gil, "La Constitución y su entorno: Estudios sobre el Anteproyecto de Constitución”, Obras completas, t. VII, ed. Espasa Calpe, Madrid, 1989.

Antonio Hernández Gil, El cambio político español y la Constitución, Planeta, Barcelona, 1982.

Antonio López Pina, "Los principios rectores de la política social y económica", en Comentarios a la Constitución española de 1978, dir. Óscar Alzaga Villaamil, t. IV, Cortes Generales/Editorial de Derecho Reunidas, 1996.

Antonio-Enrique Pérez Luño, "Las generaciones de derechos humanos", en Historia de los Derechos Fundamentales, T. IV, Vol. I, Libro I, Parte I, Dykinson, Madrid, 2013.

Carlos Jiménez Villarejo y Cesáreo Rodríguez-Aguilera, "Las garantías de los derechos humanos en el actual proceso constituyente", en VV.AA., La izquierda y la Constitución, ed. Taula de Canvi, 1978.

Charles T. Powell, España en democracia (1975-2000), Plaza y Janés, Barcelona, 2001.

Cortes Generales, Trabajos Parlamentarios, Constitución española, t. I y II, Cortes Generales, Madrid, 1980.

Diario Arriba, de 17 de agosto de 1977 (URL: https:// recursos.march.es/linz/I13660.pdf\#Search=estatuto\%20de\%20libertades\% 20publicas)

Enrique Tierno Galván, "Sobre el Preámbulo de la Constitución española", manuscrito inédito, 1979, Fondo de Documentación Jurídica del Centro de Estudios Politicos y Constitucionales.

Esther González Hernández, Breve historia del constitucionalismo común (17871931). Exilio politico y "turismo constitucional", Editorial Ramón Areces/Universidad Rey Juan Carlos, Madrid, 2006.

Federico Abascal Gasset, "La Constitución ya está “cenada", Cuadernos para el Dialogo, de 17 de junio de 1978.

Federico Abascal Gasset, Sol Gallego-Diaz y José Luis Martínez, "A la sombra de la Guillotina”, Cuadernos para el Diálogo, 12 de agosto de 1978.

Fernando Palmero, "Siete 'padres' de la Constitución que pudieron ser nueve", (URL: $\quad$ https://www.elmundo.es/espana/constitucion-espanola-40aniversario/2018/12/05/5c07f1fcfdddffd7678b4716.html, fecha de consulta: 22 de abril de 2019).

Folleto "Programa de transición", Estatuto de Libertades Públicas, XXVII Congreso PSOE, Fondo de Documentación Jurídica del Centro de Estudios Políticos y Constitucionales.

Gregorio Peces-Barba y Eusebio Fernández García (dir.), T. I, Dykinson, Madrid, 1998.

Gregorio Peces-Barba, La democracia en España. Experiencias y reflexiones, ed. Temas de Hoy, Madrid, 1996. 
Gregorio Peces-Barba, La elaboración de la Constitución española de 1978, Centro de Estudios Constitucionales, Madrid, 1988.

Gregorio Peces-Barba, Tránsito de la modernidad y derechos fundamentales, ed. Mézquita, Madrid, 1982.

Jaime Nicolás Muñiz, "La declaración de Estado social en la Constitución de 1978", en Libro-homenaje a Manuel García Pelayo, Tomo I, Universidad Central de Venezuela, Caracas, 1980.

Joaquín Tomas Villarroya, "Proceso constituyente y nueva Constitución. Un análisis crítico", Revista de Estudios Politicos, núm. 10, 1979.

Jordi Solé Tura, Los Comunistas y la Constitución, ed. Forma, Madrid, 1978.

Jorge De Esteban y Luis López Guerra, "En defensa de la Constitución", Cuadernos para el dialogo, 15 de junio, de 1978.

Jorge De Esteban y Luis López Guerra, "La trampa del consenso", Cuadernos para el Dialogo, 27 de mayo de 19789.

Jorge De Esteban y Luis López Guerra, "Las riendas del consenso", Cuadernos para el Dialogo, 3 de julio de 1978.

Jorge De Esteban, "Proyecto de unas bases constitucionales para España (Con el acuerdo del PSOE, PNV y el Equipo de la Democracia Cristiana. Hecho en Madrid, en febrero de 1977. Documento histórico no publicado nunca integramente hasta ahora”, en, en España constitucional (1978-2018): Trayectorias y perspectivas, dir. Benigno Pendás, Esther González y Rafael Rubio (coords.), t. I., Centro de Estudios Politicos y Constitucionales, Madrid, 2018.

Jorge De Esteban, Tratado de Derecho Constitucional-I. Servicio de Publicaciones. UCM, Madrid, 2001.

José Manuel Serrano Alberca, "Actas de la Ponencia constitucional", Revista de las Cortes Generales, núm, 1, 1984.

José María Martínez de Pisón Cavero, "Las generaciones de derechos humanos", Constitución y derechos fundamentales, coords. J. Betegón Carrillo, F. J. Laporta San Miguel, L. Prieto Sanchís, J. R. de Páramo Argüelles, 2004.

José Pedro Pérez-Llorca, “¿Balance o liquidación?”, en España constitucional (1978-2018): Trayectorias y perspectivas, dir. Benigno Pendás, Esther González y Rafael Rubio (coords.), t. I., Centro de Estudios Politicos y Constitucionales, Madrid, 2018.

Karel Vasak, "Human righsts: a Thirty-Year Struggle: the Sustained efforts to give Force of Law to de Universal Declaration of Human Rights", UNESCO Courier 30: 11, United Nations Educational Scientific and Cultural Organization, Paris, November, 1977.

$\mathrm{M}^{\mathrm{a}}$ Teresa Freixes San Juan, "Crónica de una Constitución consensuada”, Revista de Estudios Políticos, núm. 40 (julio-agosto), 198.

Miguel Herrero de Miñón, "Falsas y verdaderas vías del consenso constitucional", Revista de Estudios Políticos, núm. 9, 1979.

Óscar Alzaga Villaamil, Del consenso constituyente al conflicto permanente, ed. Trotta/Fundación Alonso Martínez Escudero, Madrid, 2001. 
EL DEBATE CONSTITUYENTE SOBRE EL TÍTULO I DE LA CONSTITUCIÓN ...

Óscar Alzaga Villaamil, Derecho Politico español, 1997, Ed. Centro de Estudios Ramón Areces.

Óscar Alzaga Villaamil, La Constitución española de 1978 (Comentario sistemático), Madrid, ed. del Foro, 1978.

Pablo Castellano, "Yo sí me acuerdo". Cuadernos para el Dialogo, 22 de noviembre de 1977.

Pablo Lucas Verdú, "Constitución española de 1978 y sociedad democrática avanzada", Revista de Derecho Político, Núm. 10, 1981.

Pedro Cruz Villalón, "Formación y evolución de los derechos fundamentales", en Introducción a los derechos fundamentales, ed. Servicios Jurídicos del Estado, Madrid, 1998.

Pedro González-Trevijano, "La Constitución pintada", BOE/Real Academia de Jurisprudencia y Legislación de España, Madrid, 2018.

Raúl Canosa Usera, "Marco constitucional de la protección de los consumidores y usuarios", en Derecho de los consumidores y usuarios: una perspectiva integral, coord. X. Rodríguez- Arana Muñoz, R. Canosa Usera, L. F. López Álvarez y S. Meseguer Velasco, ed. Centro universitario Villanueva/Netbiblo, La Coruña, 2008.

Raúl Morodo, "Proceso constituyente y nueva Constitución española: Anotaciones al Preámbulo constitucional", Revista de Derecho político, núm. 1, 1978.

Remedio Sánchez Ferriz, Estudios sobre las libertades, Tirant lo Blanch, $2^{\mathrm{a}}$ ed. Valencia, 1995.

Sebastián Martín, "Derechos sociales y procesos constituyentes (1931, 1978 ¿2016?)”, Gaceta Sindical, núm. 23 (diciembre), 2014.

Soledad Gallego-Díaz y Bonifacio De la Cuadra, Bonifacio, Crónica secreta de la Constitución, Tecnos, Madrid, 1989.

Yolanda Gómez Sánchez, Derecho Constitucional europeo. Derechos y libertades, Sanz y Torres, Madrid, 2005.

Fecha de envio / Sumission date: 12/04/2019

Fecha de aceptación / Acceptance date: 9/05/2019 